\title{
A Dynamic Mass-balance Model for Phosphorus in Lakes with a Focus on Criteria for Applicability and Boundary Conditions
}

\author{
Lars Håkanson • Andreas C. Bryhn
}

Received: 18 October 2006 / Accepted: 20 August 2007 / Published online: 28 September 2007

(C) Springer Science + Business Media B.V. 2007

\begin{abstract}
This paper presents an improved version of a general, process-based mass-balance model (LakeMab/ LEEDS) for phosphorus in entire lakes (the ecosystem scale). The focus in this work is set on the boundary conditions, i.e., the domain of the model, and critical tests to reveal those boundary conditions using data from a wide limnological range. The basic structure of the model, and many key equations have been presented and motivated before, but this work presents several new developments. The LakeMab-model is based on ordinary differential equations regulating inflow, outflow and internal fluxes and the temporal resolution is one month to reflect seasonal variations. The model consists of four compartments: surface water, deep water, sediment on accumulation areas and sediment on areas of erosion and transportation. The separation between the surface-water layer and the deep-water layer is not done from water temperature data, but from sedimentological criteria (from the theoretical wave base, which regulates where wind/ wave-induced resuspension of fine sediments occurs). There are algorithms for processes regulating internal fluxes and internal loading, e.g., sedimentation, resuspension, diffusion, mixing and burial. Critical model tests were made using data from 41 lakes of very
\end{abstract}

L. Håkanson $(\varangle) \cdot$ A. C. Bryhn

Department of Earth Sciences, Uppsala University,

Villavägen 16,

75236 Uppsala, Sweden

e-mail: Lars.Hakanson@geo.uu.se different character and the results show that the model could predict mean monthly TP-concentrations in water very well (generally within the uncertainty bands given by the empirical data). The model is even easier to apply than the well-known OECD and Vollenweider models due to more easily accessed driving variables.

Keywords Eutrophication · Mass-balance model ·

Phosphorus · Lakes · Processes · Fluxes ·

Sedimentation $\cdot$ Resuspension $\cdot$ Mixing ·

Suspended particulate matter

\section{Background and Aim}

Phosphorus abatement has substantially improved the water quality in many anthropogenically eutrophicated lakes (Sas 1989; Jeppesen et al. 2005). Models for predicting lake response from phosphorus reductions have thus far been rather imprecise and results from abatement programs have sometimes been disappointingly modest (Sas 1989). Phosphorus is since long recognised as a crucial limiting nutrient for lake primary production (Schindler 1977, 1978; Bierman 1980; Chapra 1980; Boynton et al. 1982; Wetzel 1983; Persson and Jansson 1988; Boers et al. 1993). The literature on phosphorus in lakes is extensive. The famous Vollenweider model (Vollenweider 1968, 1976; and later versions, e.g., OECD 1982), and the analysis behind this modelling, constitutes a fundamental base for water management (Wetzel 2001; Håkanson and 
Boulion 2002). Lake modelling has gone through great changes recently with respect to predictive power.

As a consequence of the Chernobyl nuclear accident, the pulse of radionuclides that subsequently passed along European ecosystem pathways has revealed, and made it possible to quantify, important transport routes (Håkanson 2000). Many algorithms that quantify these fluxes are valid not just for radionuclides, but for most types of contaminants, e.g., for metals, nutrients and organics in most types of aquatic environments (rivers, lakes and coastal areas) and they form the basis for the mass-balance model for phosphorus in lakes presented in this work.

In aquatic modelling there exist different kinds of models, e.g., hydraulic models driven by online meteorological data (winds, temperature and precipitation). Such models cannot generally be used for predictions over longer periods than 2 to 3 days since it is not possible to make reliable weather forecasts for longer periods that that. These models may be excellent tools in science and may give descriptive power rather than long-term predictive power. There are also different types of ecosystem-oriented modelling approaches for nutrients and toxins (see, e.g., Vollenweider 1968; Chapra 1980; OECD 1982; Monte et al. 2005). However, there are major differences between the model discussed here and other models related to differences in target variables (from conditions at individual sites to mean values over larger areas), modelling scales (daily to annual predictions), modelling structures (from using empirical/ regression models to the use of ordinary or partial differential equations) and driving variables (whether accessed from standard monitoring programs, climatological measurements or specific studies). To make meaningful model comparisons is not a simple matter, and this is not the focus here, although we will make brief model comparisons between the results from this model (LakeMab/LEEDS; see previous development stages presented by Håkanson and Boulion 2002; Malmaeus and Håkanson 2004; Dahl et al. 2006) and two well-known models in lake management, which are also driven by easily accessed driving variables, the Vollenweider model and the OECD model.

The aim of this work is to improve a model that is process-based in the sense that it should handle all important fluxes regulating the concentration of the target variable (total phosphorus) in lakes in general. As far as we know, there exist no nutrient mass- balance models of the type presented here (except from our group at Uppsala University) accounting for, e.g., tributary inflow, surface and deep-water mixing, sedimentation of particulate $\mathrm{P}$, resuspension, diffusion and outflow in a general manner designed to achieve practical utility and monthly variations in most/all types of lakes. Since different stages of this massbalance modelling have been presented by several members of our team, the aim of this work is not to repeat those stages or the details in this ongoing development, but rather to focus on the new aspects related to the boundary conditions of the model.

In this paper, we will first briefly present the studied lakes and the utilized data. In the Appendix, we will go through the more detailed set-up of the modelling. We will demonstrate how well the model works when tested for the studied lakes in terms of predicting the target variable (the TP concentration in water). As stressed, a very important part of this work has been to try to find and define the model domain, i.e., where the model does and does not apply. Finding these limits has meant that the model looks bigger but defining the model domain is very important for the practical use and predictive power of the model.

\section{Data and Methods}

\subsection{Studied Lakes and Utilized Data}

In this work, data from 41 lakes from the northern hemisphere are used. Tables 1 and 2 give a compilation of data on latitude (from 28.6 to $68.5^{\circ} \mathrm{N}$ ), lake area (from 0.014 to $3,555 \mathrm{~km}^{2}$ ), maximum depth (from 4.5 to $449 \mathrm{~m}$ ), mean depth (from 1.2 to $177 \mathrm{~m}$ ), annual precipitation (from 600 to $1,900 \mathrm{~mm} /$ year), drainage area (from 0.11 to $44,200 \mathrm{~km}^{2}$ ), altitude (11 to 850 m.a.s.1.), empirical TP-concentrations in water (from 4 to $1,100 \mu \mathrm{g} / \mathrm{l}$ ). These lakes cover a very wide domain in terms of size and form as well as geographical distribution and trophic status. The lakes were selected based on the following two criteria: (1) They had been thoroughly studied and (2) there were either laketypical data available for steady-state conditions regarding TP-concentrations (as expressed in Table 2), or long time series with data covering a large part of the history that preceded the eutrophication period. For lakes with long time series available, median TP values were calculated (see Table 2) and used in the 
Table 1 Data for the 41 studied lakes (more data are given in Table 2)

\begin{tabular}{|c|c|c|c|c|c|c|c|c|}
\hline Lake name & $\begin{array}{l}\text { Latitude } \\
\left({ }^{\circ} \mathrm{N}\right)\end{array}$ & $\begin{array}{l}D_{\max } \\
(\mathrm{m})\end{array}$ & $\begin{array}{l}D_{\mathrm{m}} \\
(\mathrm{m})\end{array}$ & $\begin{array}{l}\text { Area } \\
\left(\mathrm{km}^{2}\right)\end{array}$ & $\begin{array}{l}\text { Precipitation } \\
\text { (mm/year) }\end{array}$ & $\begin{array}{l}\text { Drainage area } \\
\left(\mathrm{km}^{2}\right)\end{array}$ & $\begin{array}{l}\text { Altitude } \\
\text { (m.a.s.1.) }\end{array}$ & $\begin{array}{l}\text { References }^{\mathrm{a}} \\
\text { (see } \\
\text { Table 3) }\end{array}$ \\
\hline Washington & 47.6 & 65.2 & 32.9 & 87.6 & 890 & 1,500 & 20 & $\mathrm{a}$ \\
\hline Blue chalk & 45.2 & 23 & 8.5 & 0.52 & 1,034 & 1.06 & 320 & $\mathrm{~b}$ \\
\hline Chub & 45.2 & 27 & 8.9 & 0.34 & 1,034 & 2.72 & 320 & $\mathrm{~b}$ \\
\hline Crosson & 45.1 & 25 & 9.2 & 0.57 & 1,034 & 5.22 & 320 & $\mathrm{~b}$ \\
\hline Dickie & 45.2 & 12 & 5 & 0.94 & 1,034 & 4.06 & 320 & $\mathrm{~b}$ \\
\hline Harp & 45.4 & 37.5 & 13.3 & 0.71 & 1,034 & 4.71 & 320 & $\mathrm{~b}$ \\
\hline Plastic & 45.2 & 16.3 & 7.9 & 0.32 & 1,034 & 0.96 & 320 & $\mathrm{~b}$ \\
\hline Red chalk & 45.2 & 38 & 14.2 & 0.57 & 1,034 & 5.32 & 320 & $\mathrm{~b}, \mathrm{c}$ \\
\hline Mendota & 43.0 & 23 & 12.3 & 39.4 & 768 & 604 & 850 & $\mathrm{~d}$ \\
\hline Peipsi & 58.5 & 15.3 & 7.1 & 3,555 & 600 & 44,200 & 29.5 & e \\
\hline Mjøsa & 60.7 & 449 & 153 & 365 & 740 & 17,369 & 122 & $\mathrm{f}$ \\
\hline Mirror & 43.9 & 11 & 5.8 & 0.15 & 1,311 & 1.03 & 213 & $\mathrm{~g}$ \\
\hline Vättern & 58.3 & 128 & 39.8 & 1,856 & 600 & 4,500 & 88 & $\mathrm{~h}$ \\
\hline S Bergundasjön & 57.0 & 5.4 & 2.4 & 4.3 & 750 & 45.1 & 160 & $\mathrm{j}$ \\
\hline Wahnbachtalsperre & 50.8 & 42 & 16 & 1.3 & 811 & 54 & 130 & $\mathrm{k}$ \\
\hline Fuschlsee & 47.8 & 67 & 37.7 & 2.66 & 1,500 & 26.8 & 663 & 1 \\
\hline Bryrup Langsø & 56.0 & 9 & 5 & 0.38 & 700 & 48.2 & 40 & $\mathrm{~m}$ \\
\hline Salten Langsø & 56.1 & 12 & 4.1 & 3.05 & 700 & 165 & 40 & $\mathrm{~m}$ \\
\hline Walensee & 47.0 & 145 & 101 & 24.2 & 1,700 & 505 & 419 & $\mathrm{n}$ \\
\hline Maggiore & 45.7 & 370 & 177.4 & 213 & 1,700 & 6,400 & 194 & o \\
\hline Biwa & 35.2 & 104 & 38.3 & 680 & 1,900 & 3,170 & 85 & $\mathrm{p}$ \\
\hline Gjersjøen & 59.8 & 64 & 23 & 2.68 & 1,043 & 84.5 & 42 & $\mathrm{q}$ \\
\hline Võrtsjärv & 57.8 & 6 & 2.8 & 270 & 670 & 3,104 & 34 & $\mathrm{r}$ \\
\hline Tegernsee & 47.4 & 72.2 & 36.3 & 9.1 & 1,500 & 200.9 & 725 & $\mathrm{~s}$ \\
\hline Schliersee & 47.4 & 40.3 & 23.9 & 2.22 & 1,500 & 24.8 & 780 & $\mathrm{~s}$ \\
\hline Stugsjön & 68.5 & 4.5 & 1.2 & 0.017 & 1,000 & 0.11 & 600 & $\mathrm{t}$ \\
\hline Magnusjaure & 68.5 & 5.5 & 2.2 & 0.014 & 1,000 & 0.12 & 600 & $\mathrm{t}$ \\
\hline Lough Neagh & 54.4 & 24 & 8.9 & 387 & 860 & 4,465 & 15 & $\mathrm{u}$ \\
\hline Geneva & 46.4 & 309 & 172 & 503 & 900 & 7,395 & 372 & $\mathrm{v}$ \\
\hline Östra Ringsjön & 55.9 & 16 & 5 & 20.8 & 850 & 325 & 54 & $\mathrm{y}$ \\
\hline Västra Ringsjön & 55.9 & 6 & 3.4 & 15.4 & 850 & 347 & 54 & $\mathrm{y}$ \\
\hline Kolbotnvannet & 59.8 & 18.5 & 10.3 & 0.30 & 1,043 & 3.9 & 95 & $\mathrm{z}$ \\
\hline Lugano & 46.0 & 288 & 171 & 27.5 & 1,700 & 270 & 271 & aa \\
\hline Apopka & 28.6 & 6 & 1.6 & 125 & 1,200 & 1,370 & 20 & $\mathrm{ab}$ \\
\hline Bullaren & 60.0 & 26.2 & 10.1 & 8.3 & 850 & 199 & 100 & $\mathrm{ac}$ \\
\hline Långsjön & 60.0 & 6.2 & 2.1 & 0.13 & 811 & 3.2 & 100 & ad \\
\hline Balaton & 47.0 & 11 & 3.2 & 596 & 600 & 5,280 & 106 & $\mathrm{ac}$ \\
\hline Batorino & 54.5 & 5.5 & 3.0 & 6.3 & 650 & 93 & 165 & ac \\
\hline Miastro & 54.5 & 11.3 & 5.4 & 13.1 & 650 & 133 & 165 & $\mathrm{ac}$ \\
\hline Naroch & 54.5 & 24.8 & 9.0 & 79.6 & 650 & 279 & 163 & $\mathrm{ac}$ \\
\hline Erken & 59.3 & 20.7 & 9 & 23.7 & 660 & 141 & 11 & $\mathrm{ac}$ \\
\hline Minimum & 28.6 & 4.5 & 1.2 & 0.014 & 600 & 0.11 & 11 & \\
\hline Maximum & 68.5 & 449 & 177.4 & 3,555 & 1,900 & 44,200 & 850 & \\
\hline Mean & 52 & 60 & 28 & 208 & 990 & 2,380 & 250 & \\
\hline
\end{tabular}

${ }^{a}$ Some data on latitude, precipitation and altitude emanate from various standard maps and surveys.

These are obligatory driving variables for the LakeMab model and the ranges inform about the model domain.

comparisons between LakeMab, the Vollenweider model and the OECD model. Whenever available, long time series covering several years were also used to test modelled data from LakeMab against empirical data.
Some of these results are presented here and others may be presented in future works. The literature references given in Table 3 provide more information on the lakes and the reliability and variability of the data. 
Table 2 Empirical data on water discharge $(Q$; needed to run the static models but not LakeMab), TP concentrations related to all kinds of TP loading to the lakes, empirical TP concentrations in the lakes, either the whole lake or the surface-water (=outflow) compartment

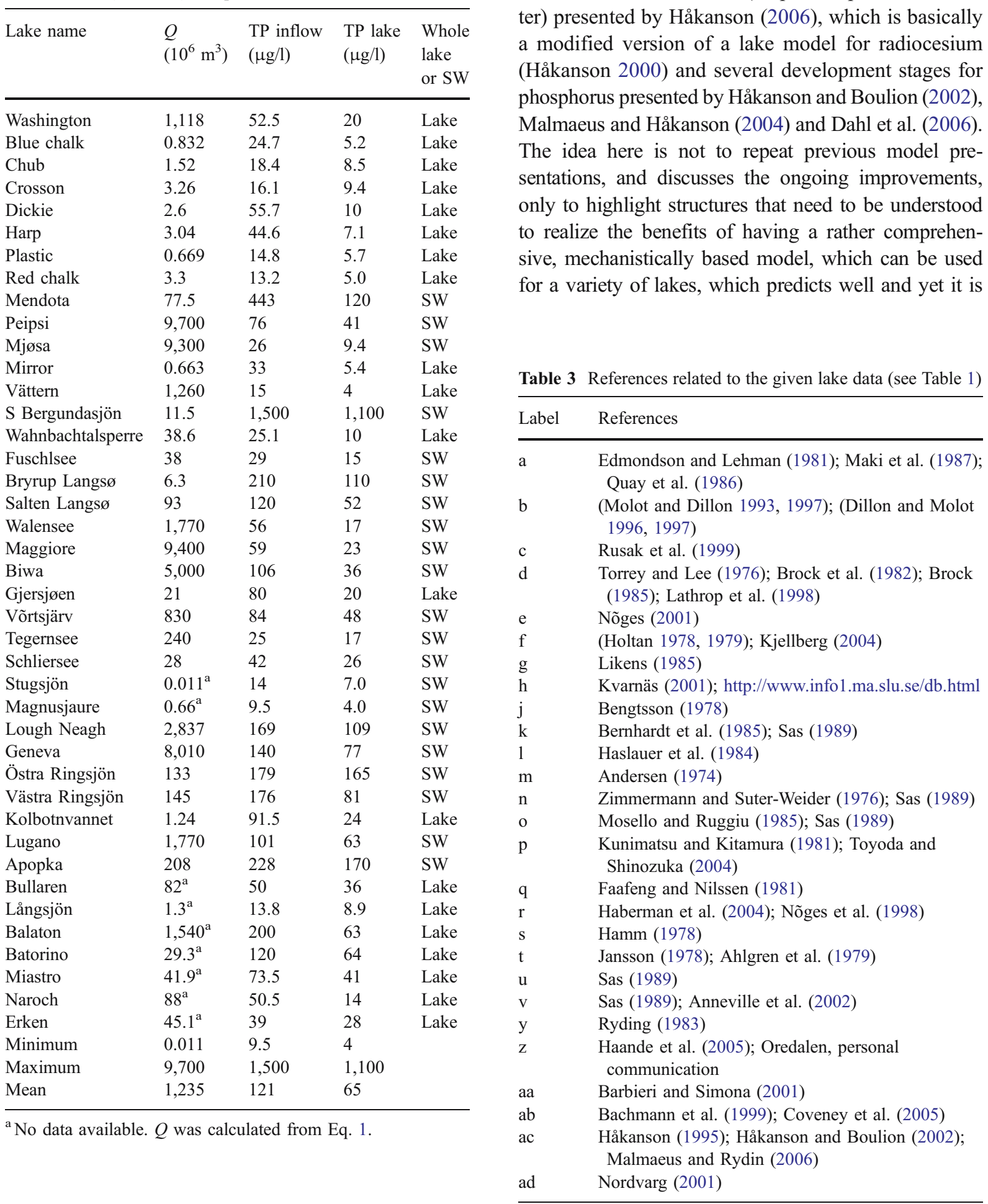

\section{The LakeMab Model for TP}

The basic structure of this model comes from the LakeMab model for SPM (suspended particulate matter) presented by Håkanson (2006), which is basically phosphorus presented by Håkanson and Boulion (2002), Malmaeus and Håkanson (2004) and Dahl et al. (2006). sentations, and discusses the ongoing improvements, 
Table 4 A compilation of the differential equations for the lake model using data from Mirror Lake
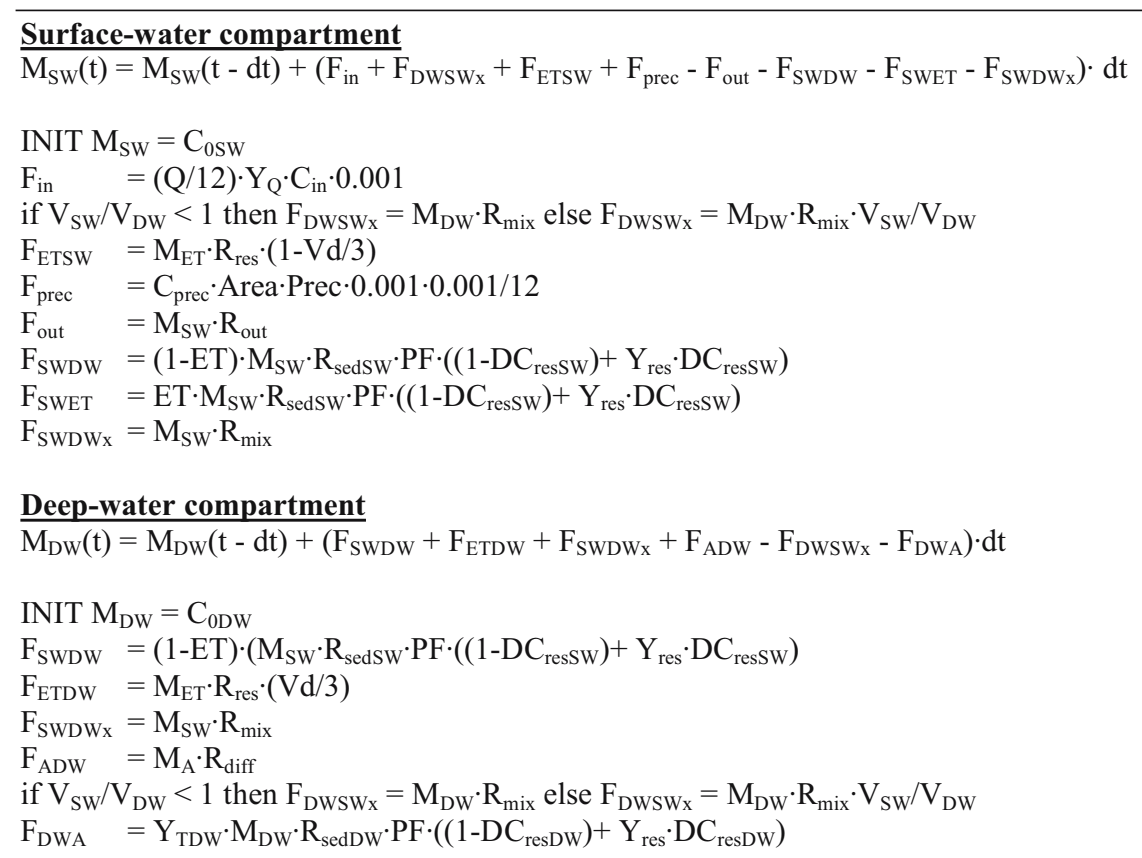

\section{ET-areas}

$\bar{M}_{\mathrm{ET}}(\mathrm{t})=\mathrm{M}_{\mathrm{ET}}(\mathrm{t}-\mathrm{dt})+\left(\mathrm{F}_{\mathrm{SWET}}-\mathrm{F}_{\mathrm{ETDW}}-\mathrm{F}_{\mathrm{ETSW}}\right) \cdot \mathrm{dt}$

INIT $\mathrm{M}_{\mathrm{ET}}=\mathrm{C}_{0 \mathrm{ET}}$

$\mathrm{F}_{\mathrm{SWET}}=\mathrm{M}_{\mathrm{SW}} \cdot \mathrm{R}_{\mathrm{sedSW}} \cdot \mathrm{PF} \cdot \mathrm{ET} \cdot\left(\left(1-\mathrm{DC}_{\mathrm{resSW}}\right)+\mathrm{Y}_{\mathrm{res}} \cdot \mathrm{DC}_{\mathrm{resSW}}\right)$

$\mathrm{F}_{\mathrm{ETDW}}=\mathrm{M}_{\mathrm{ET}} \cdot \mathrm{R}_{\mathrm{res}} \cdot(\mathrm{Vd} / 3)$

$\mathrm{F}_{\mathrm{ETSW}}=\mathrm{M}_{\mathrm{ET}} \cdot \mathrm{R}_{\mathrm{res}} \cdot(1-\mathrm{Vd} / 3)$

\section{Active A-sediments}

$\mathrm{M}_{\mathrm{A}}(\mathrm{t})=\mathrm{M}_{\mathrm{A}}(\mathrm{t}-\mathrm{dt})+\left(\mathrm{F}_{\mathrm{DWA}}-\mathrm{F}_{\mathrm{ADW}}-\mathrm{F}_{\text {bur }}\right) \cdot d \mathrm{t}$

INIT $\mathrm{M}_{\mathrm{A}}=\mathrm{C}_{0 \mathrm{~A}}$

$\mathrm{F}_{\mathrm{DWA}}=\mathrm{Y}_{\mathrm{TDW}} \cdot\left(\left(\mathrm{M}_{\mathrm{DW}} \cdot \mathrm{R}_{\mathrm{sedDW}} \cdot \mathrm{PF} \cdot\left(1-\mathrm{DC} \mathrm{res}_{\mathrm{rW}}\right)+\mathrm{M}_{\mathrm{DW}} \cdot \mathrm{R}_{\mathrm{sedDW}} \cdot \mathrm{Yres}_{\mathrm{D}} \cdot \mathrm{DC}_{\mathrm{res} D W}\right)\right.$

$\mathrm{F}_{\mathrm{ADW}}=\mathrm{M}_{\mathrm{A}} \cdot \mathrm{R}_{\text {diff }}$

$\mathrm{F}_{\text {bur }} \quad=\mathrm{M}_{\mathrm{A}} \cdot\left(1.396 / \mathrm{T}_{\mathrm{A}}\right)$

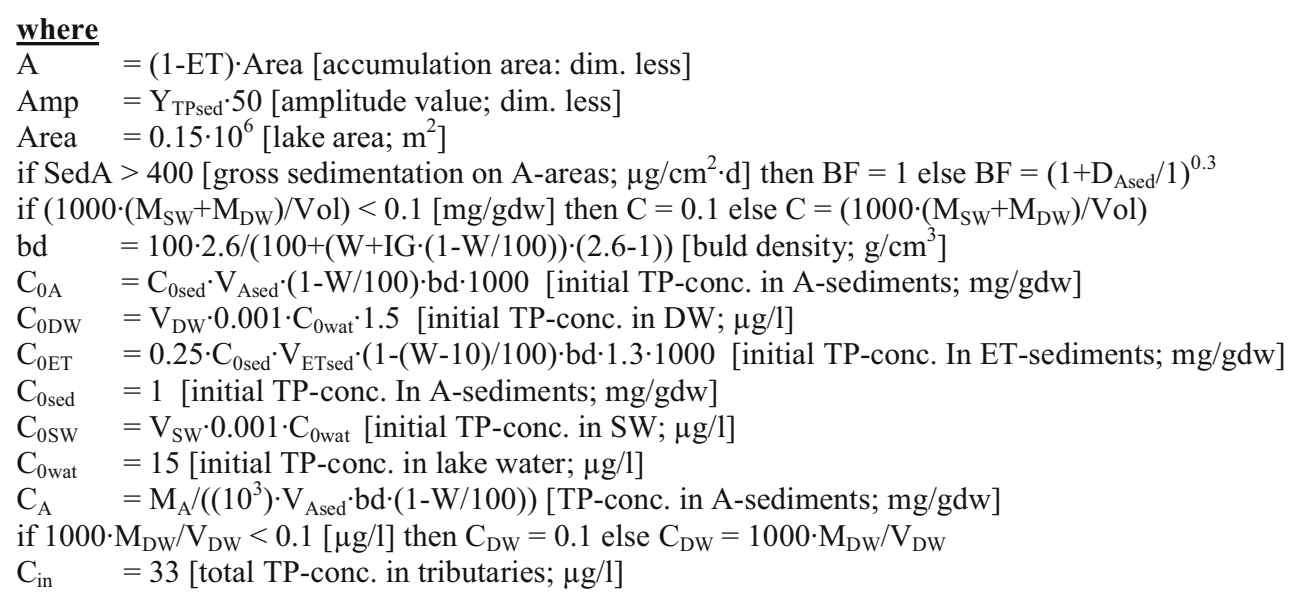


Table 4 (continued)

$\mathrm{C}_{\text {prec }}=5$ [TP-conc. in precipitation; $\left.\mu \mathrm{g} / \mathrm{l}\right]$

$\mathrm{C}_{\mathrm{SW}}=1000 \cdot \mathrm{M}_{\mathrm{SW}} / \mathrm{VS}_{\mathrm{W}}[\mathrm{TP}$-conc. in $\mathrm{SW} ; \mu \mathrm{g} / \mathrm{l}]$

if $\left(D_{\max }-D_{w b}\right) / 2<1$ [average water depth of $A$-area; $m$ ] then $D_{A}=1$ else $D_{A}=\left(D_{\max }-D_{w b}\right) / 2$

$\mathrm{D}_{\text {Ased }}=10$ [thickness of surficial A-sediment layer; $\mathrm{cm}$ ]

$\mathrm{DC}_{\mathrm{reSDW}}=\mathrm{F}_{\mathrm{ETDW}} /\left(\mathrm{F}_{\mathrm{ETDW}}+\mathrm{F}_{\mathrm{SWDW}}+\mathrm{F}_{\mathrm{SWDW}}+\mathrm{F}_{\mathrm{ADW}}\right)$ [distribution coefficient for resuspended fraction in DW; dim. less]

$\mathrm{DC}_{\text {resSW }}=\left(\mathrm{F}_{\mathrm{ETSW}}\right) /\left(\mathrm{F}_{\text {in }}+\mathrm{F}_{\mathrm{ETSW}}+\mathrm{F}_{\text {prec }}+\mathrm{F}_{\mathrm{DWSW}}\right)$ [distribution coefficient for resuspended fraction in SW; dim. less]

$\mathrm{D}_{\mathrm{ET}}=\mathrm{D}_{\mathrm{wb}} / 2$ [average water depth of ET-area; $\mathrm{m}$ )

$\mathrm{D}_{\mathrm{m}} \quad=5.75$ [mean lake depth; $\left.\mathrm{m}\right]$

$\mathrm{D}_{\max }=11$ [maximum lake depth; $\left.\mathrm{m}\right]$

$\mathrm{DR}=\left(\text { Area } \cdot 10^{-6}\right)^{0.5} / \mathrm{D}_{\mathrm{m}}$ [dynamic ratio; dim. less]

if $45.7 \cdot \sqrt{ }\left(\right.$ Area $\left.\cdot 10^{-6}\right) /\left(21.4+\mathrm{S} \sqrt{ }\left(\right.\right.$ Area $\left.\left.\cdot 10^{-6}\right)\right)>0.98 \cdot \mathrm{D}_{\max }[\mathrm{m}]$ then $\mathrm{D}_{\mathrm{TA} 1}=0.98 \cdot \mathrm{D}_{\max }$ else

$\mathrm{D}_{\mathrm{TA} 1}=45.7 \cdot \sqrt{ }\left(\right.$ Area $\left.\cdot 10^{-6}\right) /\left(21.4+\mathrm{S} \sqrt{ }\left(\right.\right.$ Area $\left.\left.\cdot 10^{-6}\right)\right)$

if $\mathrm{D}_{\mathrm{TA} 1}<1[\mathrm{~m}]$ then $\mathrm{D}_{\mathrm{wb}}=1$ else $\mathrm{D}_{\mathrm{wb}}=\mathrm{DTA} 1$ [boundary condition for the wave base]

$\mathrm{DWT}=$ deep-water temperature in ${ }^{\circ} \mathrm{C}$ from temperature sub-model $\}$

if ET3 > 0.99 [fraction of ET-areas; dim. less] then ET $=0.99$ else ET $=$ ET3

ET1 $=1-\left(\left(D_{\max }-D_{\mathrm{wb}}\right) /\left(\mathrm{D}_{\max }+\mathrm{D}_{\mathrm{wb}} \cdot \operatorname{EXP}\left(3-\mathrm{Vd}^{1.5}\right)\right)\right)^{(0.5 / \mathrm{Vd})}$

if ET1 $>0.95$ [dim. less] then ET2 $=0.95$ else ET2 $=$ ET1

if ET2 $<0.15$ [dim. less] then ET3 $=0.15$ else ET3 = ET2 [boundary condition for ET]

$\mathrm{GS} \quad=\mathrm{SMTH}(\mathrm{SedA}, 60, \mathrm{SedA})$ [gross sedimentation on A-areas; $\mu \mathrm{g} / \mathrm{cm}^{2} \cdot \mathrm{d}$ ]

if $\mathrm{W}>75$ [water content of A-sediments; \% ww] then $\mathrm{IG}=\left(1280+(\mathrm{W}-75)^{3}\right) / 207$ else $\mathrm{IG}=\mathrm{W} / 11.9$

Lat $=43.9$ [latitude; $\left.{ }^{\circ} \mathrm{C}\right]$

MAET $=\left\{{ }^{\circ} \mathrm{C}\right.$, mean annual surface-water temperature; from temperature sub-model $\}$

$\mathrm{PF} \quad=0.56$ [particulate fraction of phosphorus in lake water; dim. less]

Prec $=1311$ [mean annual precipitation; $\mathrm{mm} / \mathrm{yr}]$

$\mathrm{Q}=\left\{\right.$ mean annual water discharge; $\mathrm{m}^{3} / \mathrm{yr}$, from water discharge sub-model $\}$

$\mathrm{Q}_{\mathrm{SWDW}}=\mathrm{F}_{\mathrm{SWDWx}} /\left(\mathrm{C}_{\mathrm{SW}} \cdot 0.001\right)$ [water transport to DW from SW; $\mathrm{m}^{3} / \mathrm{month}$ ]

$\mathrm{R}_{\text {diff }}=\mathrm{Y} \cdot \mathrm{R}_{\text {diffo }} \cdot \mathrm{Y}_{\text {DRdiff }} \mathrm{Y}_{\text {sed }} \cdot(\mathrm{DWT} / 4) \cdot \mathrm{Y}_{\mathrm{TPA}}$ [diffusion rate; $1 /$ month]

$\mathrm{R}_{\mathrm{diffO}}=0.0003 / 12$ [default diffusion rate; $1 /$ month]

$\mathrm{R}_{\text {mix }}=$ Strat1 [mixing rate; $1 /$ month]

$\mathrm{R}_{\text {out }} \quad=\mathrm{Y}_{\mathrm{Q}} \cdot \mathrm{Y}_{\text {evap }} \cdot \mathrm{Y}_{\text {prec }} /\left(12 \cdot \mathrm{T}_{\mathrm{SW}}\right)$ [outflow rate; $1 /$ month]

$\mathrm{R}_{\text {res }} \quad=1 / \mathrm{T}_{\mathrm{ET}}$ [resuspension rate; $1 /$ month]

$\mathrm{R}_{\text {sedDW }}=\mathrm{Y}_{\mathrm{SPMDW}} \cdot \mathrm{v} / \mathrm{D}_{\mathrm{A}}$ [sedimentation rate to DW; $1 /$ month]

$\mathrm{R}_{\text {sedSW }}=\mathrm{Y}_{\mathrm{SPMSW}} \cdot \mathrm{v} / \mathrm{D}_{\mathrm{ET}}$ [sedimentation rate to $\mathrm{SW} ; 1 /$ month]

Sed $=\operatorname{Sed}_{\mathrm{A}} \cdot \mathrm{T}_{\text {dur }} \cdot 10^{-6} \cdot(100 /(100-\mathrm{W})) \cdot(1 / \mathrm{bd})$ [mean annual deposition on A-area; $\mathrm{cm} / \mathrm{yr}$ ]

$\operatorname{Sed}_{\mathrm{A}}=\mathrm{F}_{\mathrm{DWA}} \cdot 10^{5} /(30 \cdot 2 \cdot \mathrm{A})\left[\right.$ sedimentation on A-area; $\mu \mathrm{g} / \mathrm{cm}^{2} \cdot \mathrm{d}$ ]

$\mathrm{SPM}=10^{\wedge}(1.56 \cdot \log (\mathrm{C})-1.64)$ [suspended particulate matter concentration; $\mathrm{mg} / \mathrm{l}$ ]

$\mathrm{SPM}_{\mathrm{DW}}=10^{\wedge}\left(1.56 \cdot \log 10\left(\mathrm{C}_{\mathrm{DW}}\right)-1.64\right)$ [SPM-conc. in DW; $\left.\mathrm{mg} / \mathrm{l}\right]$

$\mathrm{SPM}_{\mathrm{SW}}=10^{\wedge}\left(1.56 \cdot \log 10\left(\mathrm{C}_{\mathrm{SW}}\right)-1.64\right)[\mathrm{SPM}$-conc. in $\mathrm{SW} ; \mathrm{mg} / \mathrm{l}]$

if ABS(SWT-DWT) $<4\left[{ }^{\circ} \mathrm{C}\right]$ then Strat $=1$ else Strat $=1 /$ ABS(SWT-DWT)

if MAET $>17\left[{ }^{\circ} \mathrm{C}\right]$ or DR $>3.8$ or MAET $<4$ then Strat $1=1$ else Strat $1=$ Strat

$\mathrm{SWT}=$ s surface-water temperature; ${ }^{\circ} \mathrm{C}$, from temperature sub-model $\}$

$\mathrm{T} \quad=$ Vol/Q [theoretical water retention time; $\mathrm{yr}$ ]

$\mathrm{T}_{\mathrm{A}}=12 \cdot \mathrm{BF} \cdot \mathrm{D}_{\mathrm{Ased}} /$ Sed [age of A-sediments; months]

if $\mathrm{TA}<12$ [months] then $\mathrm{T}_{\mathrm{A} 1}=12$ else $\mathrm{T}_{\mathrm{A} 1}=\mathrm{TA}$

if TA1 $>12 \cdot 250$ then TA2 $=12 \cdot 250$ else TA2 $=$ TA1 [boundary conditions for $\mathrm{T}_{\mathrm{A}}$ ]

$\mathrm{T}_{\text {dur }}=-0.058 * \mathrm{Lat}^{2}+0.549 \cdot \mathrm{Lat}+365$ [duration of growing season; days]

if $\mathrm{V}_{\mathrm{DW}} / \mathrm{Q}_{\mathrm{SWDW}}<0.5$ [months] then $\mathrm{T}_{\mathrm{DW}}=0.5$ else $\mathrm{T}_{\mathrm{DW}}=\mathrm{V}_{\mathrm{DW}} / \mathrm{Q}_{\mathrm{SWDW}}$

if $\mathrm{Y}_{\mathrm{DR} 2}<1$ [months] then $\mathrm{T}_{\mathrm{ET}}=1$ else $\mathrm{T}_{\mathrm{ET}}=\mathrm{Y}_{\mathrm{DR} 2}$ [boundary conditions for mixing]

$\mathrm{T}_{\mathrm{SW}}=\mathrm{V}_{\mathrm{SW}} / \mathrm{Q}$ [theoretical surface-water retention time; months]

$\mathrm{v} \quad=\mathrm{v}_{\mathrm{def}} \cdot \mathrm{Y}_{\mathrm{DR}}$ [settling velocity; $\mathrm{m} /$ month]

$\mathrm{V}_{\text {Ased }}=\mathrm{A} \cdot 0.01 \cdot\left(\mathrm{D}_{\text {Ased }} \cdot \mathrm{Vd} / 3\right)$ [volume of A-sediments; $\left.\mathrm{m}^{3}\right]$

$\mathrm{Vd}=3 \cdot \mathrm{D}_{\mathrm{m}} / \mathrm{D}_{\max }[$ form factor; dim. less]

$\mathrm{v}_{\text {def }} \quad=6$ [default settling velocity; $\mathrm{m} / \mathrm{month}$ ]

$\mathrm{V}_{\mathrm{DW}}=\left(\mathrm{Vol}_{\mathrm{SW}}\right)$ [deep-water volume; $\mathrm{m}^{3}$ ] 
Table 4 (continued)

$\mathrm{V}_{\mathrm{ETsed}}=($ Area-A $) \cdot 0.01 \cdot(\mathrm{DAsed} \cdot 0.1 \cdot \mathrm{Vd} / 3)$ [volume of ET-sediments; $\mathrm{m}^{3}$ ]

$\mathrm{Vol}=$ Area $\cdot \mathrm{D}_{\mathrm{m}}\left[\right.$ lake volume; $\left.\mathrm{m}^{3}\right]$

$\mathrm{V}_{\mathrm{SW}}=\left(\right.$ Area $\left.\cdot \mathrm{D}_{\mathrm{m}}-\mathrm{A} \cdot \mathrm{Vd} \cdot\left(\mathrm{D}_{\max }-\mathrm{D}_{\mathrm{wb}}\right) / 3\right)$ [volume of surface-water compartment; $\mathrm{m}_{3}$ ]

if $\mathrm{V}_{\mathrm{SW}} / \mathrm{V}_{\mathrm{DW}}>30$ (days) then 30 else $\mathrm{V}_{\mathrm{SW}} / \mathrm{V}_{\mathrm{DW}}$ [boundary condition for mixing]

if $\mathrm{DR}>6$ then $\mathrm{W}=65$ else if $\mathrm{DR}>0.5$ then $\mathrm{W}=75$ else if $\mathrm{DR}>0.045$ then $\mathrm{W}=85$ else $\mathrm{W}=95$ [prediction of water content of A-sediments; \% ww]

if $\mathrm{DR}<0.26$ then $\mathrm{Y}_{\mathrm{DR}}=\mathrm{DR} / 0.26$ else $\mathrm{Y}_{\mathrm{DR}}=0.26 / \mathrm{DR}$ [boundary condition for settling velocity]

$\mathrm{Y}_{\mathrm{DR} 2}=12 \cdot \mathrm{DR} / 0.26$

if DR $>0.26$ then $Y_{D W}=\sqrt{ }\left(T_{D W} \cdot 365 / 12+1\right)$ else $Y_{D W}=\sqrt{ }(D R / 0.26) \cdot \sqrt{ }\left(T_{D W} \cdot 365 / 12+1\right)$ [boundary condition for

settling velocity in DW]

if $\mathrm{DR}<3.8$ then $\mathrm{Y}_{\text {DRDiff }}=1$ else $\mathrm{Y}_{\text {DRDiff }}=3.8 / \mathrm{DR}$

if $Y_{\mathrm{DW}}>20$ then $\mathrm{Y}_{\mathrm{DW} 1}=20$ else $\mathrm{Y}_{\mathrm{DW} 1}=\mathrm{Y}_{\mathrm{DW}}$ [boundary condition for settling velocity in DW]

if $\mathrm{SWT}<9\left({ }^{\circ} \mathrm{C}\right)$ then $\mathrm{Y}_{\text {evap }}=1$ else $\square \mathrm{Y}_{\text {evap }}=(1-0.4(\mathrm{SWT} / 9-1))$ [dimensionless moderator for evaporation regulating outflow from lake]

if Prec $<650(\mathrm{~mm} / \mathrm{yr})$ then $\mathrm{Y}_{\text {prec }}=(1+1.8 \cdot(\operatorname{Prec} / 650-1))$ else $\mathrm{Y}_{\text {prec }}=(1+0.5 \cdot(\operatorname{Prec} / 650-1))$ [dim. moderator for precipitation regulating outflow from lake]

$\mathrm{Y}_{\mathrm{Q}}=$ \{seasonal moderator for $\mathrm{Q}$; from sub-model for water discharge $\}$

$\mathrm{Y}_{\mathrm{res}}=\left(\mathrm{T}_{\mathrm{ET}}+10\right)$ [dim. moderator for resuspension]

if $\operatorname{Sed}_{\mathrm{A}}<50\left(\mu \mathrm{g} / \mathrm{cm}^{2} \cdot \mathrm{d}\right)$ then $\mathrm{Y}_{\text {sed }}=(2-1 \cdot(\mathrm{GS} / 50-1))$ else $\mathrm{Y}_{\text {sed }}=(2+\mathrm{Amp} \cdot(\mathrm{GS} / 50-1))$ [dim. moderator for sedimentation in the algorithm for diffusion]

$\mathrm{Y}_{\mathrm{SPMDW}}=\left(1+0.75 \cdot\left(\mathrm{SPM}_{\mathrm{DW}} / 50-1\right)\right)$ [dim. moderator expressing SPM-influences on settling velocity in DW]

$\mathrm{Y}_{\mathrm{SPMSW}}=\left(1+0.75 \cdot\left(\mathrm{SPM}_{\mathrm{SW}} / 50-1\right)\right)$ [dim. moderator expressing SPM-influences on settling velocity in SW]

if $\mathrm{DR}>0.26$ then $\mathrm{Y}_{\mathrm{TDW}}=\mathrm{Y}_{\mathrm{TDW} 2}$ else $\mathrm{Y}_{\mathrm{TDW}}=\sqrt{ }(\mathrm{DR} / 0.26) \cdot \mathrm{Y}_{\mathrm{TDW} 2}$ [dim. moderator for $\mathrm{T}_{\mathrm{DW}}$ ]

if $\mathrm{T}_{\mathrm{DW}} \cdot 365 / 12>\mathrm{T} \cdot 365$ then $\mathrm{Y}_{\mathrm{TDW} 1}=\mathrm{T} \cdot 365$ else $\mathrm{Y}_{\mathrm{TDW} 1}=\mathrm{T}_{\mathrm{DW}} \cdot 365 / 12$ [dim. moderator for diffusion]

if $\mathrm{Y}_{\mathrm{TDW} 1}<1$ then $\mathrm{Y}_{\mathrm{TDW}}=1$ else $\mathrm{Y}_{\mathrm{TDW}}=\sqrt{ }\left(\mathrm{Y}_{\mathrm{TDW} 1} / 1\right)$ [dim. moderator for diffusion]

if $\mathrm{C}_{\mathrm{A}}<0.5(\mathrm{mg} / \mathrm{g} \mathrm{dw})$ then $\mathrm{Y}_{\mathrm{TPA}}=0$ else $\mathrm{Y}_{\mathrm{TPA}}=\left(\mathrm{C}_{\mathrm{A}}-0.5\right)$ [dim. moderator for diffusion]

$\mathrm{Y}_{\mathrm{TPsed}}=\left(\mathrm{C}_{\mathrm{A}} / 2\right)$ [dim. moderator in the algorithm for diffusion]

driven by few and readily accessible driving variables. The model is described in the Appendix and equations and abbreviations are complied in Table 4.

\subsection{The Panel of Driving Variables}

Table 1 gives the panel of driving variables except for the fact that data on TP concentration in tributaries (including all contributing sources of TP discharged into the given lake, micrograms per liter) are also needed to run this model. No other parts of the model should be changed unless there are good reasons to do so. An important demand for LakeMab is that all obligatory driving variables should be easy to access. This is an evident criterion for the practical utility of the model. The OECD and the Vollenweider models use the same driving variables, $C_{\text {in }}(\mu \mathrm{g} / \mathrm{l})$ and $T$ (year). The Vollenweider model may be written as: $C=C_{\text {in }} /(1+\sqrt{ } T)$.

Evidently, this is a very simple model. It is important to have reliable data on $C_{\text {in }}$ to run the models and this is also important in using the LakeMab model. $T$ is defined from the ratio between lake volume ( $\mathrm{Vol}$ in cubic meters) and water discharge ( $Q$ in cubic meters per year). To determine Vol, one needs a bathymetric map of the lake, which also informs about lake area, mean depth $\left(D_{\mathrm{m}}\right)$ and maximum depth $\left(D_{\max }\right)$, which are used in LakeMab. The major difference between the OECD and Vollenweider models, on one hand, and LakeMab on the other, is that to run LakeMab, one does not require reliable empirical data on $Q$, since there is a sub-model to predict $Q$ from data on latitude, altitude and annual precipitation. These three parameters are generally easier to access for most lakes than reliable empirical data on $Q$. So, it should be easier to use LakeMab than the other two models.

\subsection{The Output Variables}

Basically, LakeMab is meant to predict TP concentrations in water (the entire lake water, in surface water and/or in deep water), but the model is process-based 
and can also provide information about many important variables, e.g., TP in sediments, fluxes, amounts, temperatures, SPM, sedimentation, sediment characteristics, the dynamic ratio, the form factor, percentage of ET areas, surface and deep water volumes, etc. A list of output variables from LakeMab is given in Table 5 .

The question is: Will LakeMab predict better or worse than the two standard models?

\section{Results}

This section first gives initial results to illustrate how the model works for a few selected lakes, then we will give results for all 41 tested lakes, including a comparison with predictions using the OECD and the Vollenweider models. Note that in the following tests, there has been no tuning of LakeMab. Only the obligatory driving variables (from the panel of driving variables, see Table 1) have been changed for each lake. We have used empirical and not modelled data on $Q$ for the predictions using the OECD and the Vollenweider models.

The results of the test will be presented in the following way. First, comparisons between empirical data, uncertainties in empirical data and modelpredicted values will be given for some randomly selected lakes. A basic question is: how well does the model predict considering all the uncertainties in the empirical data used to run the model and the assumptions behind the given algorithms?
Figure 1a gives the mean empirical annual TP concentrations in surface water in Lake Geneva and the mean annual TP concentration in the tributary (including all TP emissions to the lake). The idea with this figure is to stress how two time series of the most important empirical driving variable, the TP concentration in tributary(ies) $\left(C_{\mathrm{TPin}}\right)$ and of empirical lake data to test model predictions actually and typically look. Empirical data are "not cut in stone" but uncertain and this will set limits to the predictive power. We will use a standard monthly coefficient of variation $(\mathrm{CV}=\mathrm{SD} / \mathrm{MV})$ of 0.35 (from Håkanson and Peters 1995), as calculated from many studied lakes over several years, as a reference value for the inherent uncertainty in the empirical lake TP data. We will give confidence intervals for the median empirical TP concentrations and compare these values to the modelled TP concentrations in water $\left(C_{\mathrm{TP}}=C\right)$. From Fig. 1a, one can note that there is only a rather poor co-variation between the TP concentrations in the tributary and in the surface water in Lake Geneva. Several peaks and low values in the inflowing water are not reflected in the lake water, as one might have expected if these inflow lows and peaks actually existed. It is well known that the $\mathrm{CV}$ for river variables should be higher than the $\mathrm{CV}$ for the same lake variables (Håkanson 1999, 2006). This means that one would expect a significantly higher monthly CV than 0.35 for TP in the inflowing river water. Figure $1 \mathrm{~b}$ shows empirical lake data from the surface water with the corresponding uncertainty bands

Table 5 List of key output variables from the default set-up of the LakeMab model

\begin{tabular}{|c|c|}
\hline Classification & Key output variables \\
\hline TP concentrations & $\begin{array}{l}\text { In lake water }\left(C_{\mathrm{TP}} \text { or } C\right) \text {, in surface-water }\left(C_{\mathrm{SW}}\right) \text {, in deep-water }\left(C_{\mathrm{DW}}\right) \text {, in surficial }(0-10 \mathrm{~cm}) \text { A sediments } \\
\left(C_{\mathrm{A}}\right) \text { and in surficial ET sediments }\left(C_{\mathrm{ET}} \approx 0.25 \cdot C_{\mathrm{A}}\right)\end{array}$ \\
\hline Fluxes & $\begin{array}{l}\text { Inflow }\left(F_{\text {in }}\right) \text {, outflow }\left(F_{\text {out }}\right) \text {, direct atmospheric TP fallout onto the lake surface }\left(F_{\text {prec }}\right) \text {, sedimentation from } \\
\text { SW to ET areas }\left(F_{\text {SWET }}\right) \text {, sedimentation from SW to DW }\left(F_{\text {SWDW }}\right) \text {, sedimentation from DW to A areas } \\
\left(F_{\text {DWA }}\right) \text {, resuspension from ET areas to SW }\left(F_{\text {ETS }} W\right) \text {, resuspension from ET areas to DW }\left(F_{\text {ETDW }}\right) \text {, mixing } \\
\text { from SW to DW }\left(F_{\text {SWDWx }}\right) \text {, mixing from DW to SW }\left(F_{\text {DWSWx }}\right) \text {, burial }\left(F_{\text {bur }}\right)\end{array}$ \\
\hline Amounts & $\begin{array}{l}\text { TP in the } \mathrm{SW} \text { compartment }\left(\mathrm{M}_{\mathrm{SW}}\right), \mathrm{TP} \text { in } \mathrm{DW}\left(M_{\mathrm{DW}}\right), \mathrm{TP} \text { in sediments from ET areas }\left(M_{\mathrm{ET}}\right) \text { and } \mathrm{TP} \text { in } \\
\text { surficial }(0-10 \mathrm{~cm}) \text { A sediments }\left(M_{\mathrm{A}}\right)\end{array}$ \\
\hline Lake variables & $\begin{array}{l}\text { Surface-water temperature (SWT), deep-water temperature (DWT), concentration of suspended particulate } \\
\text { matter }(\mathrm{SPM}) \text {, sedimentation on A areas in } \mathrm{cm} / \text { year }\left(\mathrm{Sed}_{\mathrm{A}}\right) \text {, age of deposits on ET areas }\left(T_{\mathrm{ET}}\right) \text {, age of } \\
\text { sediments }(0-10 \mathrm{~cm}) \text { on A areas }\left(T_{\mathrm{A}}\right) \text {, water content of A sediments }(0-10 \mathrm{~cm} ; W) \text {, organic content } \\
\left(=\text { loss on ignition) of A sediments }(0-10 \mathrm{~cm} ; \mathrm{IG}) \text {, The duration of the growing season }\left(T_{\mathrm{dur}}\right)\right.\end{array}$ \\
\hline Lake parameters & Dynamic ratio (DR), form factor $(\mathrm{Vd})$, Percentage of ET and A areas, SW volume $\left(V_{\mathrm{SW}}\right)$, DW volume $\left(V_{\mathrm{DW}}\right)$ \\
\hline
\end{tabular}

Note that this list does not include rates and model constants. 
Fig. 1 Results for Lake Geneva (Switzerland/ France). a Gives the empirical time series of data (months 1 to 253 for the period from January of 1964 to 1984) on TP concentrations in inflowing water and in surface water. One can note that there is a relatively poor co-variation between these two variables, which indicates that there are uncertainties in both these empirical data series. b Gives modelled TP concentrations in surface water compared to empirical data and inherent uncertainties in empirical data. c Gives a comparison between empirical data related to the surface water compartment and modelled data for the entire lake volume using LakeMab, the Vollenweider model and the OECD model
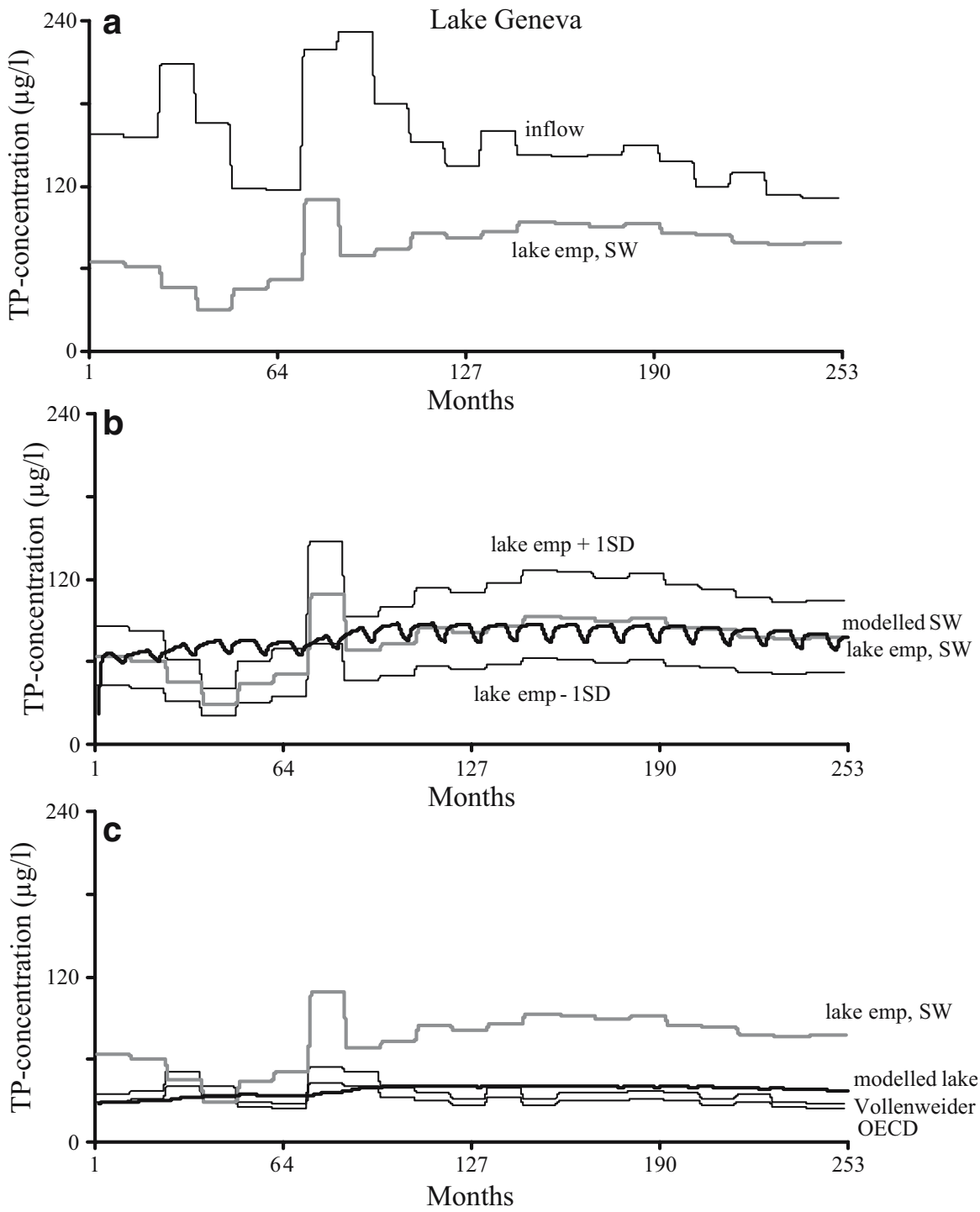

related to one standard deviation and the modelled values for Lake Geneva. We can note that the modelled values are within the empirical uncertainty bands most of the time and actually quite close to the median empirical value. Figure $1 \mathrm{c}$ gives a comparison showing TP predictions using LakeMab, the Vollenweider and the OECD models. This comparison shows that the Vollenweider and the OECD models yield much too low TP concentrations, but so does the LakeMab model for the TP concentration calculated for the entire volume. The empirical TP data do not emanate from the entire volume but from the surface-water compartment. It is not possible to predict TP concentrations in the surface water with the Vollenweider and the OECD approaches, so one should not expect these models to predict TP in surface water well in lakes where there is a significant difference between the TP concentrations in the surface water and in the deep water, as one would often expect in very deep lakes, such as Lake Geneva.

Figure 2 is included here to stress this point. The figure gives results for (a) Lake Balaton, Hungary, which is very large, shallow and eutrophic, (b) Lake Bullaren, Sweden, which is of moderate size (in this study) and mesotrophic and (c) Harp Lake, Canada, which is very small, deep and oligotrophic. The modelled TP concentrations in the surface water (SW), the deep water (DW) and the entire lake are compared 
Fig. 2 Results for a very large, shallow and eutrophic Lake Balaton, Hungary, b Lake Bullaren, Sweden, which is of moderate size (in this study) and mesotrophic and c Harp Lake, Canada, which is very small, deep and oligotrophic. The figures give modelled TP concentrations in surface water $(S W)$, deep water $(D W)$ and in the entire lake (Lake) as well an empirical median values related to the entire lake
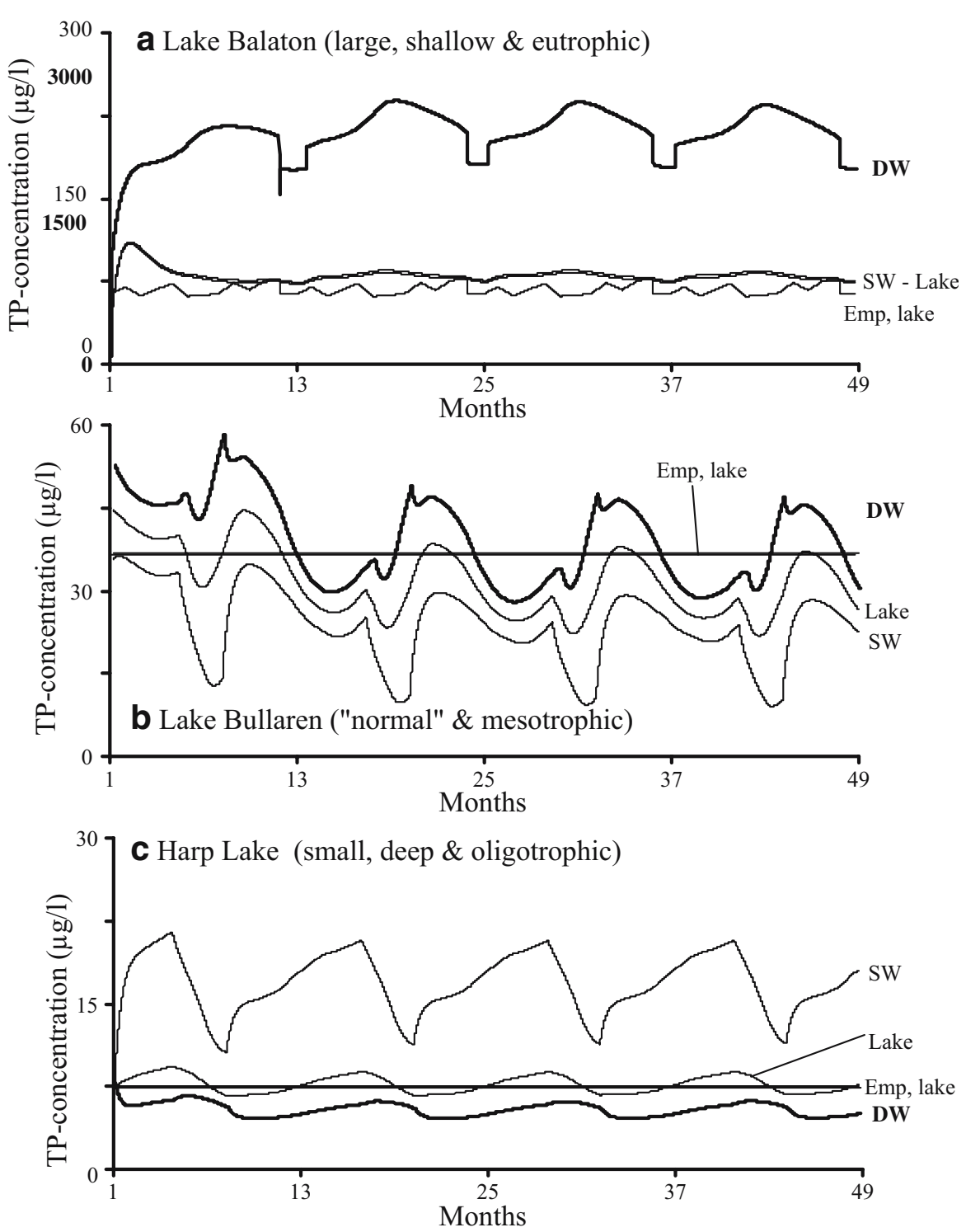

to empirical data. The TP concentration in the very limited deep-water volume in Lake Balaton are very high, but since the DW-volume is small these high values do not influence the TP concentration in the entire lake water volume very much. The conditions in Lake Bullaren are more "typical" in the sense that TP in the deep-water compartment is clearly higher than in the SW compartment. The opposite is seen in Harp Lake, where the diffusion is relatively limited because the deposition of organic materials is small, and the turbulence in the deep-water compartment is also relatively low. So, sedimentation is higher than diffusion and the TP concentration in the DW compartment is clearly lower than in the SW compartment.
Evidently, it is a major advantage that the LakeMab model can differentiate between TP concentrations in surface and in deep water.

Figure 3 gives data from Lake Östra Ringsjön, Sweden. From this, and from most of the 41 tested lakes, we do not have time series of data (as we have for Lake Geneva in Fig. 1), only a median value related to a given time period, generally between 36 years. The idea with Fig. 3 is to motivate why a few lakes have been omitted in this study. In Fig. 3a, we have simulated an initial period with a very heavy TP loading (three times higher than the actual loading), which stops abruptly after 10 years (month 121). The idea is to illustrate that the LakeMab model is 

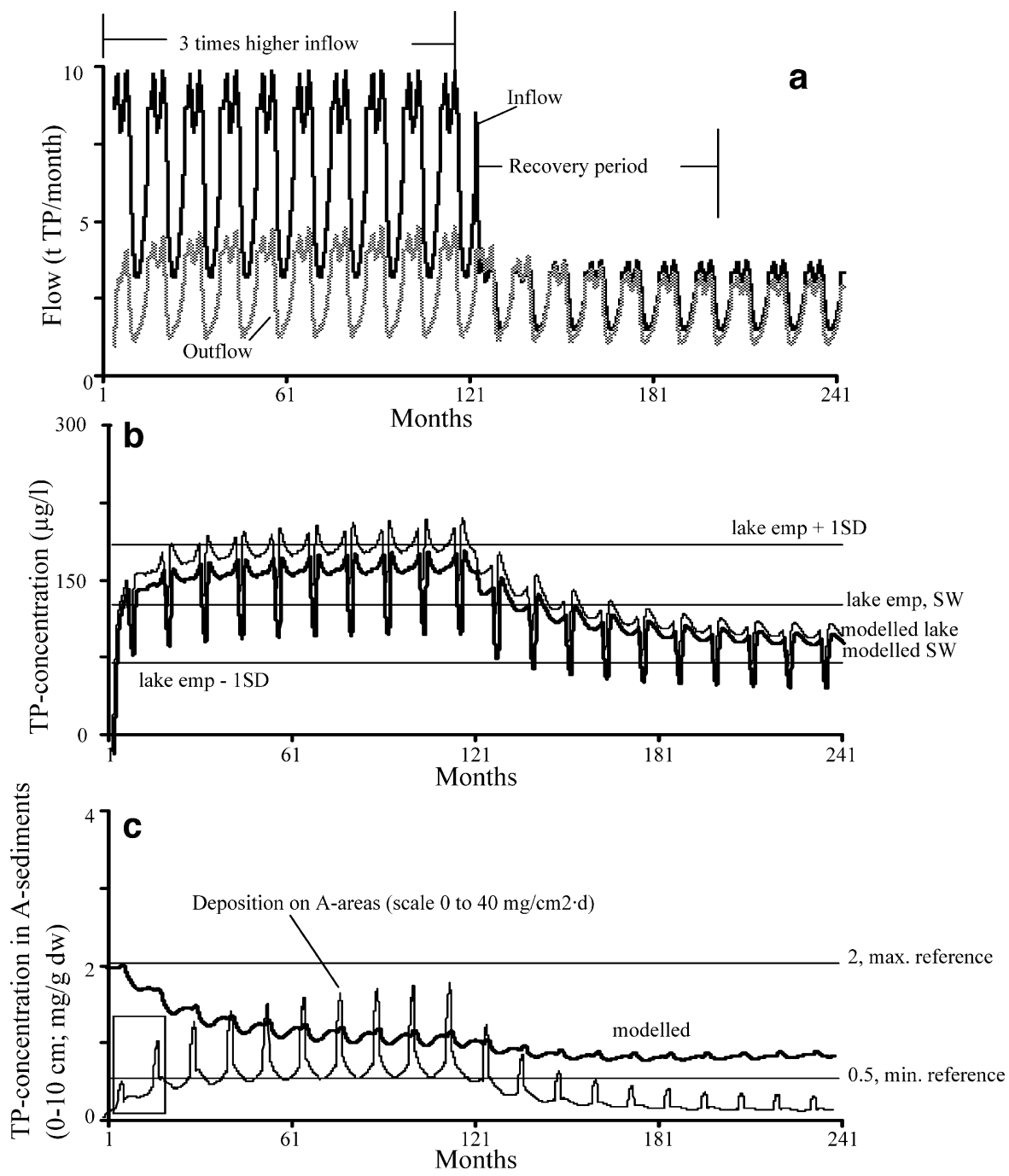

Fig. 3 Results for Lake Ö. Ringsjön (Sweden) and illustration of a recovery after a situation with a heavy phosphorus load. a Shows the initial conditions when the hypothetical inflow to the lake was set to be three times higher than the actual situation. This ends month 121 (after 10 years). One can note, that the TP outflow is higher than or close to the TP inflow for a recovery period of about 5-10 years. b Gives the corresponding modelled TP concentrations in lake water and in surface water. The empirical median value relates to the conditions in the surface

constructed to give a realistic recovery process, and Fig. 3a shows that for a fairly long time (5-7 years), the outflow of TP from the lake is higher than or close to the inflow of TP. This is only possible after a drastic reduction in TP inflow and is related to the sediments, which can act as a source after a period of high contamination (Håkanson and Jansson 1983). We have only used data from lakes in a relatively water at steady state after full recovery. This figure also gives the reference lines related to the inherent, default uncertainty in empirical TP concentrations in lakes. c Gives the corresponding modelled TP concentration in A sediments $(0-10 \mathrm{~cm})$, the two reference lines related to TP concentrations in A sediments $(0.5$ and $2 \mathrm{mg} / \mathrm{g} \mathrm{dw}$ ) and the modelled sedimentation (=deposition of matter) on A areas in milligrams per squared centimeter-d; note that the scale for this curve is between 0 and 10

steady state or with sufficient data to account for the conditions during the high contamination period. Figure $3 \mathrm{~b}$ gives the corresponding comparison between empirical lake data, inherent uncertainties in the empirical data and the modelled values. One can note that for the second phase (for which the empirical data are valid), there is also a good correspondence between modelled TP and empirical median TP. 
Figure $3 \mathrm{c}$ gives modelled TP in A sediments and the two reference lines related to the minimum TP concentration in surficial $(0-10 \mathrm{~cm})$ A sediments of $0.5 \mathrm{mg} / \mathrm{g} \mathrm{dw}$ and the maximum reference value of 2 . We can note that the modelled value is well within the expected interval. We have also added modelled values of sedimentation in Fig. 3c. The idea is to demonstrate that during the high contamination period the sedimentation is very high, but also the diffusion, which means that the TP concentration in the sediments does not increase in the same way as the TP concentration in the water. When the high contamination period stops, the accumulated TP in the sediments will continue to contaminate the lake and after a recovery period of about 5-7 years there are new steady-state concentrations in the water and the sediments.

Figure 4 gives a compilation of the results for all 41 lakes. We give regressions between empirical data (on the $y$-axes) and modelled values using LakeMab (a; logarithmic data are used because the frequency distributions are positively skewed), the Vollenweider model (a) and the OECD model (c). One can note that the scatter around the regression lines is much wider for the OECD and the Vollenweider models $\left(r^{2}=0.76\right.$ and 0.77 , respectively) and that LakeMab predicts much better $\left(r^{2}=0.96\right)$. In Fig. 5 , we give the error functions, which is a direct way to show model behaviour using actual values (and not log-data). From Fig. 5a, we can note that the mean/median error is close to zero $(0.03)$ for LakeMab and that the scatter is much smaller (the standard deviation, $\mathrm{SD}$, is 0.29 , which is very good considering the inherent uncertainty for the TP concentration in tributaries, which should be larger than 0.35 (which is the inherent monthly uncertainty for the lake TP concentrations). SD is 1.3 for Vollenweider model and 1.1 for the OECD model. Evidently, this is an excellent result for the LakeMab model.

\section{Comments and Conclusions}

This work has presented a new development stage of a dynamic mass-balance model for phosphorus in lakes (LakeMab) which handles all important fluxes of TP to, from and within lakes. This type of modelling makes it possible to perform different simulations by adding, changing or omitting fluxes, evaluate responses, and thereby be able to predict consequences of different approaches to reduce phosphorus input to a studied lake. One can get a realistic estimation of what can be expected in terms of improved environmental conditions as a result of different remedial strategies. Many of the structures in LakeMab are general and have also been used with similar success for other types of aquatic systems (coastal areas and rivers) and for other substances (mainly SPM and radionuclides; Håkanson 2000, 2006). When using the model no tuning should be performed. The model should be adjusted to a new lake only by changing the obligatory driving variables. Since the utilized driving variables emanate from standard monitoring programs or can be calculated from bathymetric maps, the model could have great practical utility in water management.

It should be stressed that this modelling is not meant to describe conditions at individual sampling sites, but to address the monthly conditions at the ecosystem-scale (for entire defined lakes). Working at this scale allows important simplifications to be made, as compared to modelling on finer spatial and temporal scales. Finally, it may be said that simplifications are always needed in modelling, and the main challenge is to find the simplest and mechanistically best model structure yielding the highest possible predictive power in critical tests using the smallest number of driving variables. The model presented here predicts with uncertainties close to those of empirical data and it is therefore probably more urgent to expand the model's domain (e.g., to tropical lakes or marine coastal areas) than to further improve the model structure for the present model domain.

The following boundary conditions are new compared to previous stages in the model development:

- The algorithm to account for the influence of turbulence (dynamic ratio) on the settling velocity for suspended particulate matter (Eq. 6).

- The general algorithm to estimate the age of resuspended particles (Eqs. 8, 9, and 10).

- The approach to calculate diffusion (Eqs. 16, 17, 18, 19, 20, 21, and 22).

- The algorithm to calculate burial (Eqs. 23, 24, 25, 26, 27, 28, 29, 30, and 31).

- $\quad$ The boundary conditions for mixing (Eqs. 35 and 36).

Many of the boundary conditions explored in this study may also be valid when the model is used for 

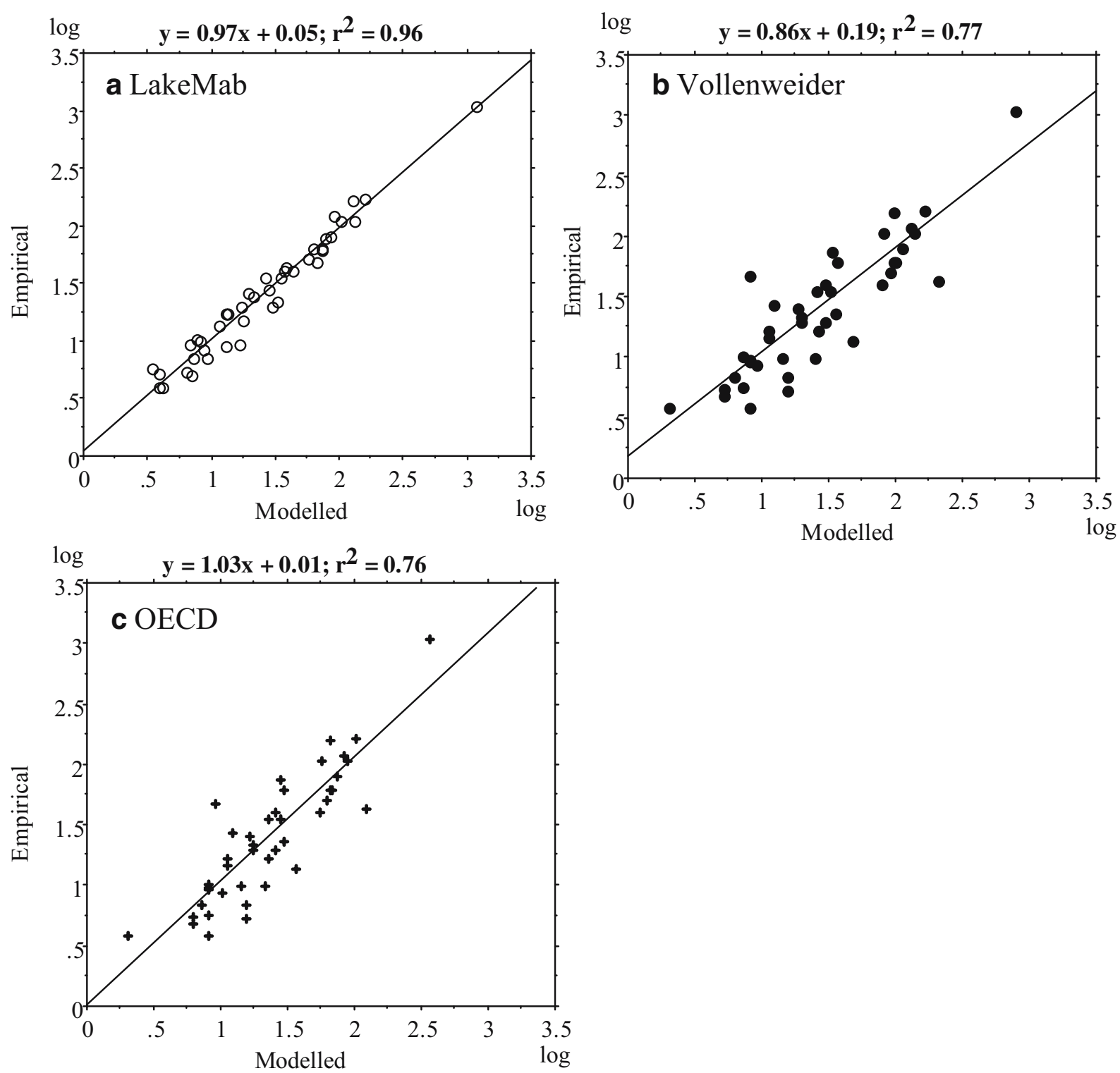

Fig. 4 A comparison between empirical and modelled TP concentrations in the studied 41 lakes, a gives results using the LakeMab model, b similar results using the Vollenwider model,

coastal areas. The only reason why we have not tested this modelling for coastal areas is that it has not been possible for us to access the kind of data (covering such a wide coastal area domain) as we have used in this study for lakes.

Acknowledgement This work has been carried out within the framework of the Thresholds project, and integrated EU project (no. 003933-2) focusing on sustainable coastal management. We would like to acknowledge the financial support from EU and the constructive cooperation within the project. Special thanks to Prof. Carlos Duarte, the scientific coordinator of the

c results for the OECD model. Note that these regressions give regression lines and $r^{2}$ values for logarithmic data (because the data are not normally distributed but positively skewed)

Thresholds project. Many of the processes incorporated in the LakeMab model are general and should apply also to CoastMab, our coastal model.

\section{Appendix}

Temperature and Water Discharge

This modelling assumes that a given lake has one or more tributaries and this means that this modelling 


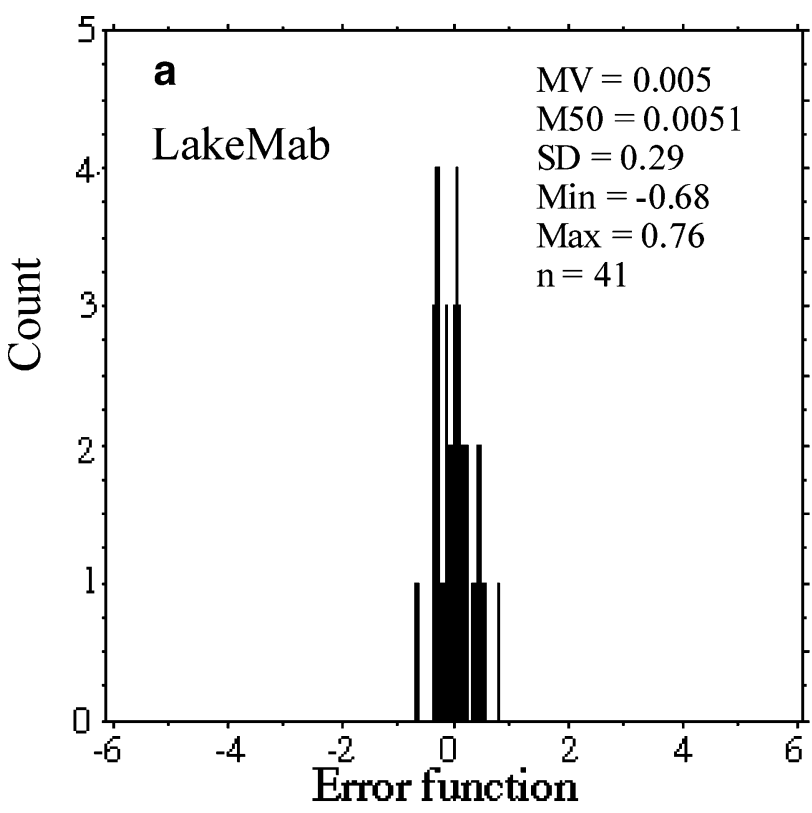

- (Emp/Mod - 1)

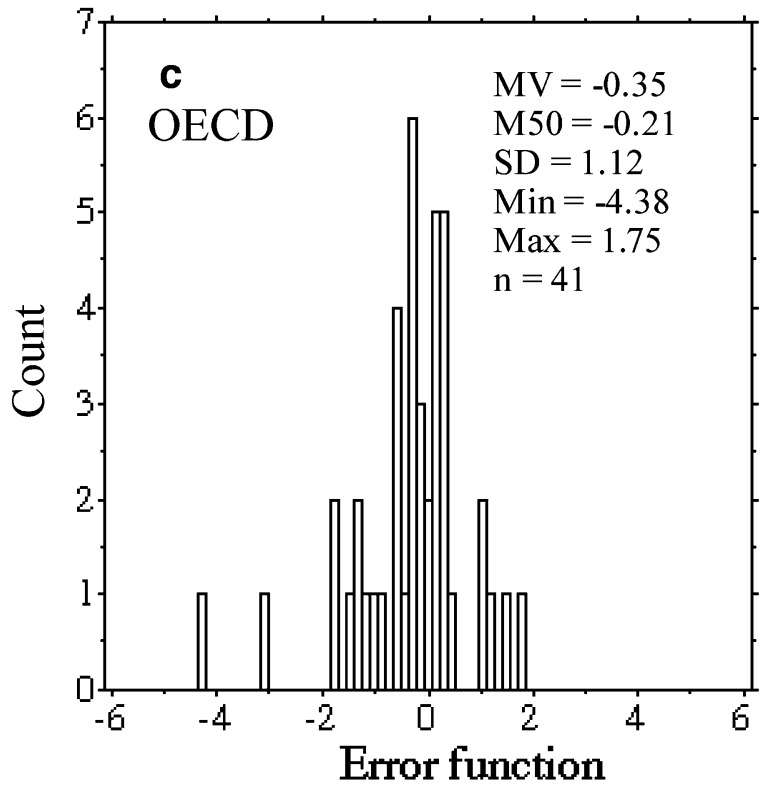

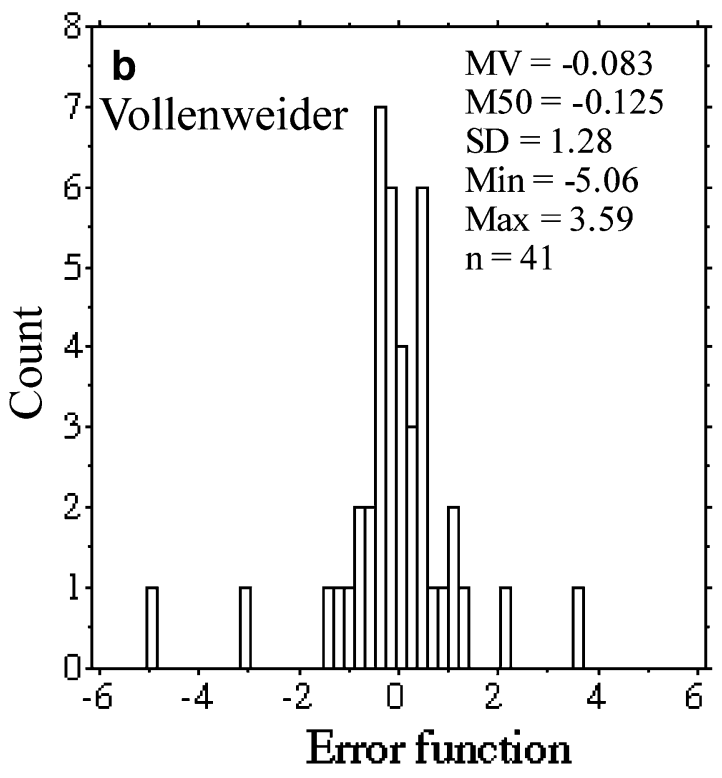

- (Emp/Mod - 1)

$+($ ModjEmp - 1)

$95 \%$ CI for emp. data $=0.35$

\section{-(Emp/Mod - 1) +(Mod'Emp - 1)}

Fig. 5 Error functions and statistics when modelled TP concentrations are compared to empirical data for the 41 lakes; a results related to the LakeMab model, $\mathbf{b}$ results for the Vollenweeider model and $\mathbf{c}$ results for the OECD model

cannot be directly applied to, e.g., hypersaline lakes or lakes mainly feed by ground water inflow.

Latitude and altitude are used to calculate surfaceand deep-water temperatures. The temperature submodel has been presented by Ottosson and Abrahamsson (1998). In this approach, only data on latitude and altitude needs to be supplied. From this, both seasonal (monthly) variations in surface and deep-water temperatures are predicted. These temperature data give information on the stratification and mixing between the surface and the deep-water volumes (Håkanson et al. 2004). 
The model for river discharge $(Q)$ used here has been presented by Abrahamsson and Håkanson (1998) to meet specific demands in ecosystem modelling. It was developed from an extensive data set from more than 200 European rivers and only requires driving available driving variable from standard maps. There will always be uncertainties concerning the proper value for $Q$. The model presented here is meant to yield predictions of $Q$, which can be accepted in ecosystem models where the focus is on, e.g., the predictive power for the concentration of pollutants in water, sediments and biota. Figure 6 exemplifies a basic component of this $Q$ model, the relationship between mean annual water discharge ( $Q$ in cubic meters per second) and the area of the drainage area (ADA in squared kilometers). From this regression, mean monthly $Q\left(Q_{\text {month }}\right)$ is calculated from mean annual $Q\left(Q_{\mathrm{yr}}\right.$ or simply $\left.Q\right)$ :

$Q_{\text {month }}=Q \cdot A D A \cdot(\operatorname{Prec} / 650) \cdot Y_{Q}$

where Prec is the mean annual precipitation, the ratio (Prec/650) is a dimensionless moderator based on the fact that the regression in Fig. 6 relates to lakes with an average mean annual precipitation of $650 \mathrm{~mm} /$ year and $Y_{\mathrm{Q}}$ is a dimensionless moderator accounting for how monthly water discharge values relate to annual values depending on variations in latitude and altitude.

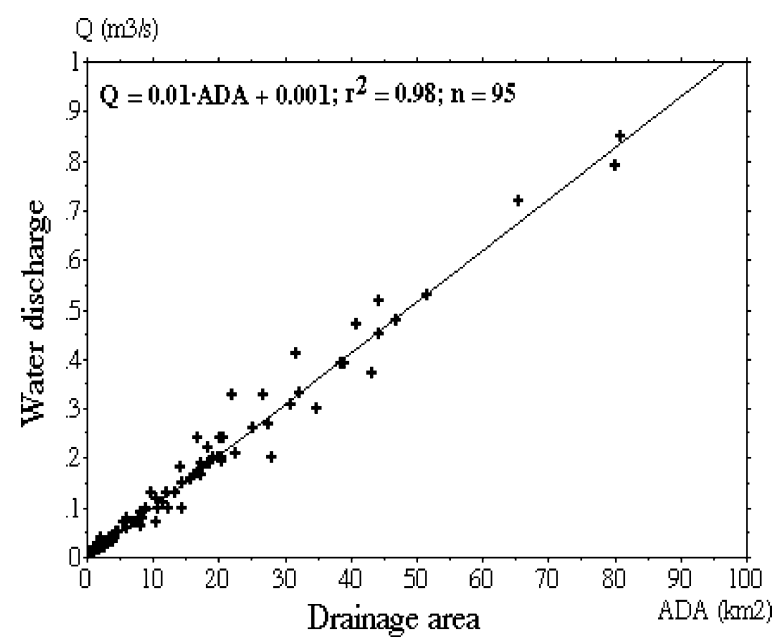

Fig. 6 The relationship between the area of the drainage area (ADA in squared kilometers) and the mean annual water discharge $(Q)$ using data from 95 catchments areas from boreal landscapes (data from Håkanson and Peters 1995)
Model Compartments

This modelling uses ordinary differential equations and the temporal resolution is one month to reflect seasonal variations. There are four main compartments (see Fig. 7): surface water, deep water, areas where, by definition, processes of fine sediment erosion and transport dominate the bottom dynamic conditions (ET areas) and areas with continuous sedimentation of fine particles, the accumulation areas (A areas; for more details on bottom dynamic conditions in lakes, see Håkanson and Jansson 1983). The inflow of TP to a given lake is handled by the following two fluxes, tributary inflow $\left(F_{\text {inQ }}\right)$ and direct atmospheric fallout $\left(F_{\text {prec }}\right)$.

Note that all TP emissions from point sources should be included in the tributary inflow. The internal transport processes of TP are: sedimentation from surface water to deep water $\left(F_{\text {SWDW }}\right)$ and to areas of erosion and transportation $\left(F_{\mathrm{SWET}}\right)$, resuspension from ET areas either back to surface water $\left(F_{\text {ETSW }}\right)$ or to deep water $\left(F_{\mathrm{ETDW}}\right)$, sedimentation from deep water on accumulation areas $\left(F_{\mathrm{DWA}}\right)$, diffusion of phosphorus from A sediments to deep water $\left(F_{\mathrm{ADW}}\right)$, upward and downward mixing, i.e., the transport from deep water to surface water $\left(F_{\text {Dwswx }}\right)$ and from surface water to deep water $\left(F_{\text {SWDWx }}\right)$ and burial $\left(F_{\text {bur }}\right)$, i.e., the transport from surficial $(0-10 \mathrm{~cm}) \mathrm{A}$ sediments to deeper sediment layers. The transport from a lake is regulated by the outflow from surface water $\left(F_{\text {out }}\right)$. All equations will be motivated in the following text and they are compiled in Table 4 .

When there is a partitioning of a flow from one compartment to two or more compartments, this is handled by a distribution coefficient (DC). This could be a default value, a value derived from a simple equation or from an extensive sub model. There are four such distribution coefficients in the TP model:

1. The DC regulating the amount in particulate and dissolved fraction. A default value for the particulate fraction, $\mathrm{PF}=0.56$, has been used in all these simulations for phosphorus, as motivated in Fig. 8.

2. The DC regulating sedimentation either to areas of erosion and transport (ET areas) above the theoretical wave base $\left(D_{\mathrm{wb}} ; F_{\mathrm{SWET}}\right)$ or to the deep-water areas beneath the theoretical wave base ( $F_{\text {SWDW }}$, see Fig. 9 ). 
Fig. 7 An outline of the structure of the dynamic lake model for phosphorus

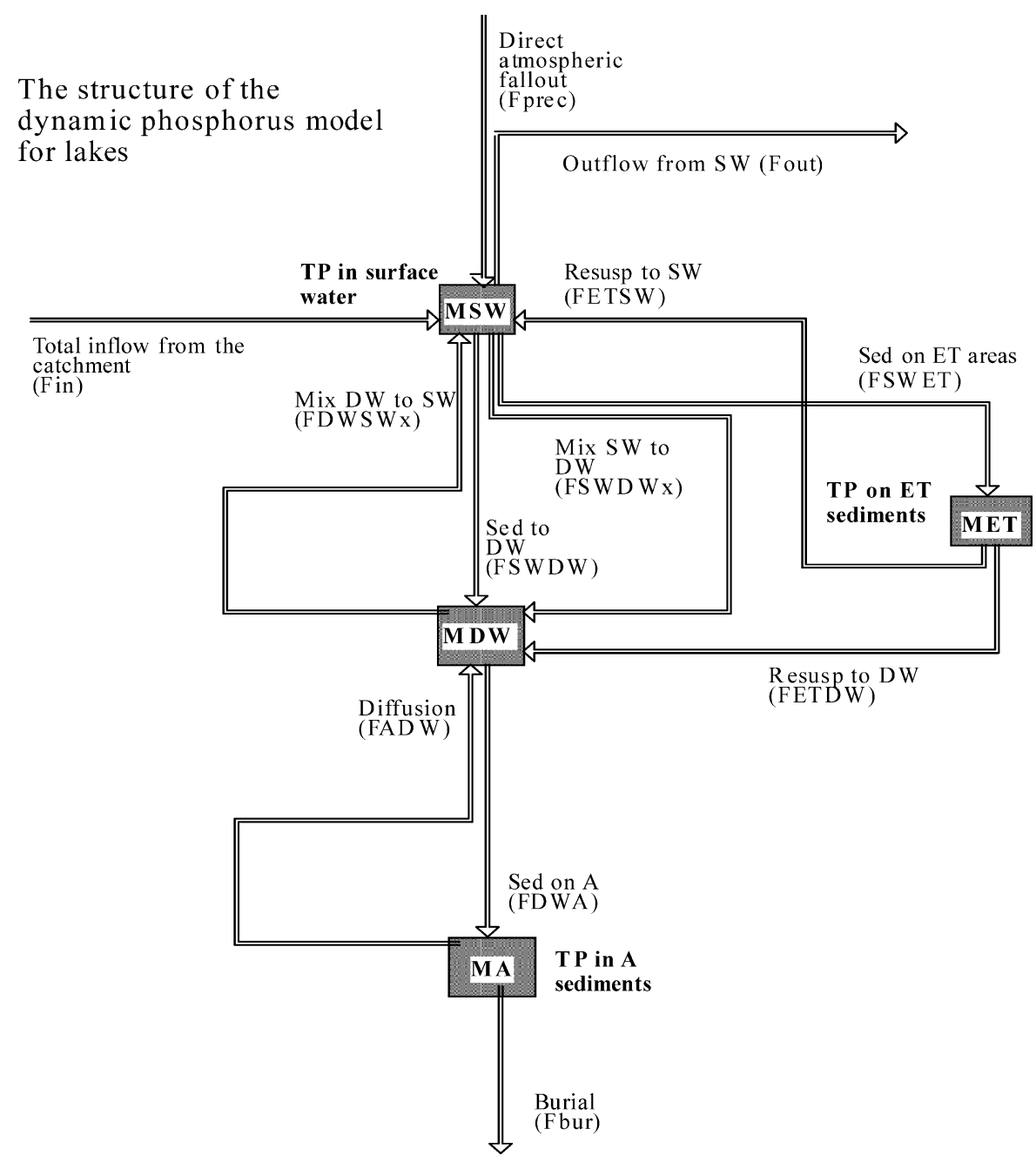

3. The DC describing resuspension flux from ET areas back either to the surface water $\left(F_{\mathrm{ETSW}}\right)$ or to the deep water compartment ( $F_{\text {ETDW }}$ ).

4. The DC describing how much of the TP in the water that has been resuspended $\left(\mathrm{DC}_{\mathrm{res}}\right)$ and how much that has never been deposited and resuspended $\left(1 \mathrm{DC}_{\mathrm{res}}\right)$.

\section{Determination of the Different Compartments}

From a mass-balance perspective, it is necessary that the four compartments (surface water, deep water, ET areas and $\mathrm{A}$ areas) included in LakeMab are defined in a relevant manner. The water depth that separates the surface-water and the deep-water compartment could potentially be related to (a) water temperature conditions and the thermocline, (b) vertical concen- tration gradients of dissolved materials or suspended particles, (c) wind/wave influences and wave characteristics and (d) sedimentological conditions associated with resuspension and internal loading (Håkanson et al. 2004). In this work, the separation is done by sedimentological criteria meaning that the volumes are separated by the theoretical wave base, $D_{\text {wb }}$ (Fig. 9, Håkanson and Jansson 1983). By definition, the theoretical wave base also determines the limit between ET and A areas. $D_{\mathrm{wb}}$ is calculated from lake area (note that the area should be in squared kilometers in Eq. 2, giving $D_{\mathrm{wb}}$ in meters), which is related to the effective fetch and how winds and waves influence the bottom dynamic conditions:

$$
D_{w b}=(45.7 \cdot \sqrt{ } \text { Area }) /(21.4+\sqrt{ } \text { Area })
$$




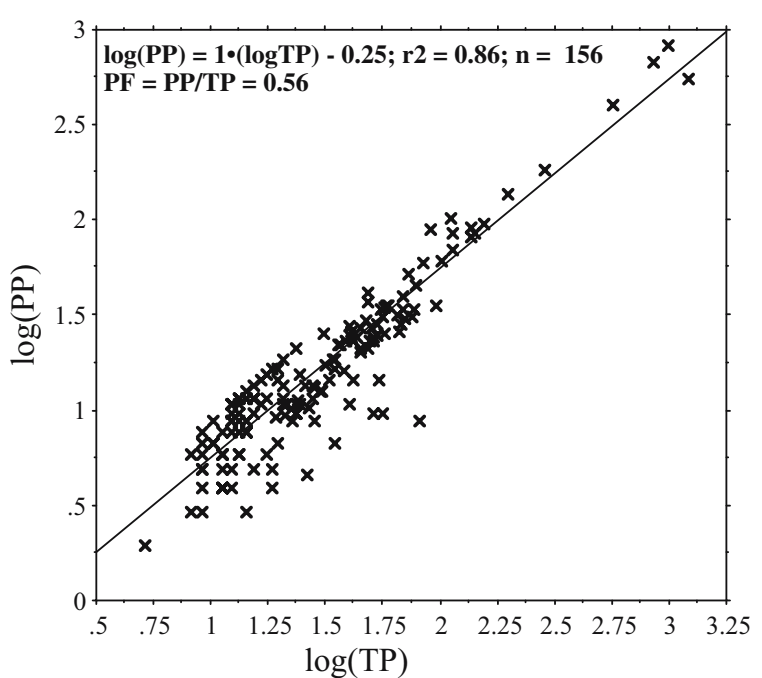

Fig. 8 The relationship between empirical PP (particulate phosphorus; logarithmic values; PP in milligrams per cubic meter) and empirical TP (total $\mathrm{P}$; logarithmic values in milligrams per cubic meter). The figure the regression line based on individual data $(n=156)$ as well as the particulate fraction $(P F)$. Data from Håkanson and Boulion (2002)

The accumulation areas $(A)$ are calculated according to Eq. 3 below (from Håkanson 1999):

$$
\begin{aligned}
& \text { Area }_{A}= \\
& \quad\left(\text { Area }\left(\left(D_{\max }-D_{w b}\right) /\left(D_{\max }+D_{w b} \cdot \operatorname{EXP}\left(3-V d^{1.5}\right)\right)\right)^{(0.5 / V d)}\right)
\end{aligned}
$$

where $A_{r e a}$ is the area below the wave base (the accumulation areas). So, to calculate $\mathrm{Area}_{\mathrm{A}}$, and hence also the ET area, Area $\mathrm{ET}_{\mathrm{T}}=$ Area- - Area $_{\mathrm{A}}$, data are needed on the maximum depth $\left(D_{\max }\right)$, the theoretical

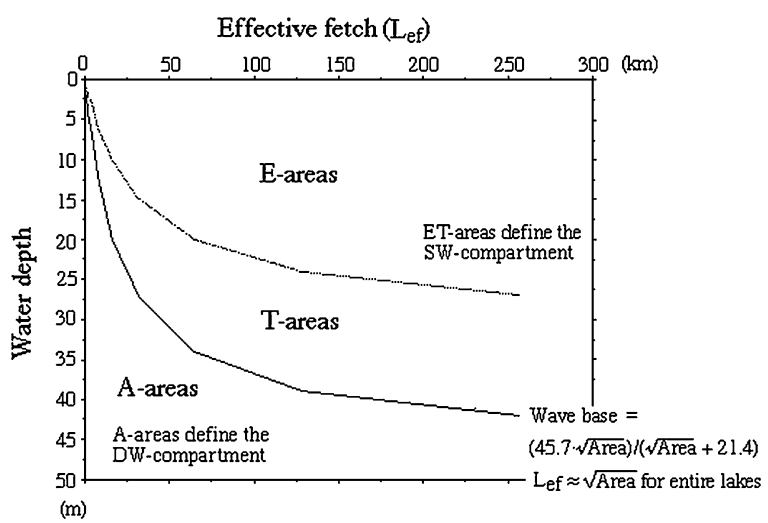

Fig. 9 The ETA diagram (erosion-transportation-accumulation; for more information, see Håkanson and Jansson 1983) illustrating the relationship between effective fetch, water depth and bottom dynamic conditions. The wave base $\left(D_{\mathrm{wb}}\right)$ can be used as a general criterion to differentiate between surface water and deep water in systems wave base $\left(D_{\mathrm{wb}}\right)$, and the form factor (=volume development $), \mathrm{Vd}\left(\mathrm{Vd}=3 \cdot D_{\mathrm{m}} / D_{\max }\right.$, where $D_{\mathrm{m}}=$ the mean depth). The fraction of ET areas $\left(\mathrm{ET}=\mathrm{Area}_{\mathrm{ET}} /\right.$ Area) is used as a dimensionless distribution coefficient. It regulates the sedimentation of particulate TP either to deep-water areas or to ET areas and hence also the amount of matter available for resuspension on ET areas. For simplicity, this approach is used also when there is an ice cover (if the surface water temperature, $\mathrm{SWT}$, is $0^{\circ} \mathrm{C}$ ). ET generally varies from 0.15 (see Fig. 10), since there must always be a shallow shore zone where processes of erosion and transport dominate the bottom dynamic conditions, to 1 in large and shallow areas totally dominated by ET areas, which is the situation in areas where $D_{\mathrm{wb}}<$ $D_{\text {max }}$. In this modelling, ET is, however, never permitted to become 1 , since one can assume that in most lakes there are deep holes, sheltered areas or macrophyte beds which would function as A areas. To estimate the fraction of ET areas in such systems the following expression is used to calculate a value for the theoretical wave base: If $D_{\mathrm{wb}}<D_{\max }$ than $D_{\mathrm{wb}}=$ $0.95 \cdot D_{\max }$.

\section{Direct Atmospheric Fallout}

The direct deposition ( $F_{\text {prec }}$ in $\mathrm{g} \mathrm{TP} /$ month) is simply and traditionally given by the mean annual precipitation multiplied by the TP concentration in the rain and the lake area, dimensional adjustments (i.e., Prec $0.001 \cdot$ Area $\cdot \mathrm{C}_{\text {TPprec }} \cdot 0.001 \cdot(1 / 12)$ in $(\mathrm{m} /$ year $) \cdot \mathrm{m}^{2} \cdot(\mathrm{g} \mathrm{TP} /$ $\left.\mathrm{m}^{3}\right) \cdot(1 /$ month $\left.)\right)$. In all following calculations, we have set $C_{\text {TPprec }}$ to $5 \mu \mathrm{g} / 1$ (Håkanson 1999).

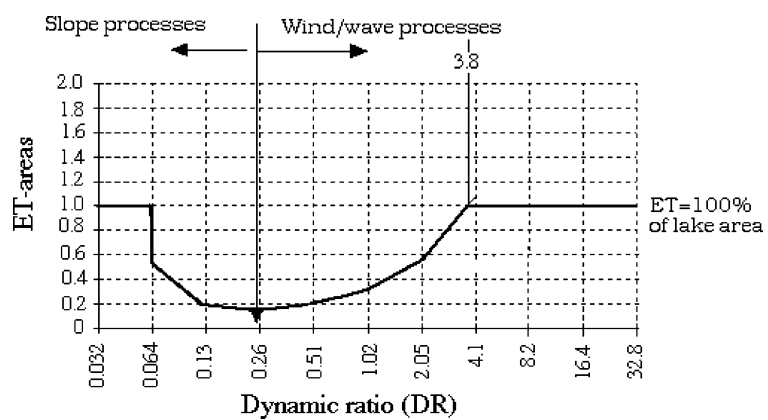

Fig. 10 Illustration of the relationship between the dynamic ratio $(D R)$ and the bottom dynamic conditions, as given by the ET areas. The higher the ET areas, the more resuspension of fine sediments, i.e., the higher the advection and turbulence (modified from Håkanson and Jansson 1983) 
River Inflow

The inflow ( $F_{\text {in }}$ in grams TP per month) to a lake from rivers (including all point source emissions) is calculated from water discharge $(Q)$ times the TP concentration in the tributary $\left(C_{\text {in }}\right)$, i.e.:

$$
\begin{aligned}
F_{\text {in }} & =Q \cdot C_{\text {in }} \\
& =A D A \cdot 0.01 \cdot(\text { Prec } / 650) \cdot Y_{Q} \cdot 60 \cdot 60 \cdot 24 \cdot 30 \cdot C_{\text {in }}
\end{aligned}
$$

The dimensionless moderator for monthly discharge, $Y_{\mathrm{Q}}$, is calculated from latitude and altitude (Abrahamsson and Håkanson 1998).

\section{Sedimentation}

Sedimentation of particulate TP depends on:

1. A default settling velocity, $v_{\text {def }}$. Here, $72 \mathrm{~m} /$ year is used as a general value for the complex mixture of substances making up SPM and the carrier particles of particulate TP in lakes (from Håkanson 2006). The default settling velocity is changed into a rate $(1 /$ month) by division with the mean depth of the surface-water areas $\left(D_{\mathrm{SW}}\right)$ for sedimentation in these areas and by the mean depth of the deep-water areas $\left(D_{\mathrm{DW}}\right)$ for sedimentation in deep-water areas. It should be noted that in most lakes the actual settling velocities are between 2 and $12 \mathrm{~m} /$ year.

2. This version of the LakeMab uses a regression model to predict SPM from dynamically modelled TP concentrations $\left(C_{\mathrm{TP}}\right.$; see Fig. 11). This regression is based on annual data from 51 lakes and coastal areas (data mainly from Lindström et al. 1999; Bryhn et al. 2006 and Håkanson 2006) and it gives a high coefficient of determination $\left(r^{2}=0.895\right)$.

3. The SPM concentration will influence the settling velocity; the greater the aggregation of suspended particles, the bigger the flocs and the faster the settling velocity (Kranck 1973, 1979; Lick et al. 1992). This is expressed by a dimensionless moderator $\left(Y_{\mathrm{SPM}}\right)$ defined by:

$$
Y_{S P M S W}=\left(1+0.75 \cdot\left(S P M_{S W} / 50-1\right)\right)
$$

This dimensionless moderator quantifies how changes in SPM in the surface water, $\mathrm{SPM}_{\mathrm{SW}}$, influence the fall velocity of the suspended particles. The amplitude value is set in such a manner that a change in $\mathrm{SPM}_{\mathrm{SW}}$ by a

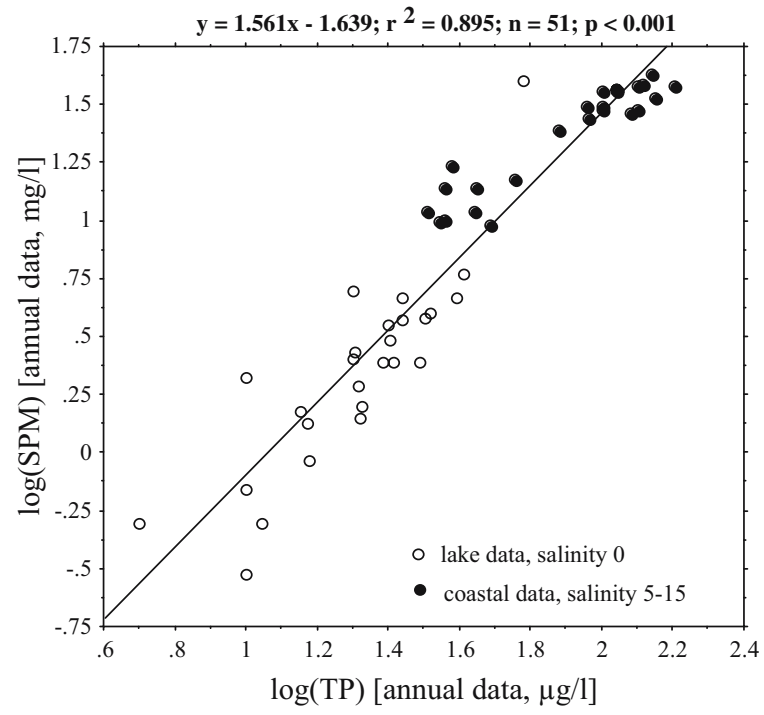

Fig. 11 The regression between SPM and TP concentrations based on data from 51 coastal areas and lakes (from Håkanson and Lindgren 2006)

factor of 10, e.g., from $2 \mathrm{mg} / 1$ (which is a typical value for low-productive lakes) to $20 \mathrm{mg} / \mathrm{l}$ (which is typical for more productive systems), will cause a change in the settling velocity by a factor of 2 . The norm value for the moderator is $50 \mathrm{mg} / \mathrm{l}$. In this modelling, SPM has a default settling velocity of $72 \mathrm{~m} /$ year in systems with SPM values of $50 \mathrm{mg} / \mathrm{l}$, and in systems with lower SPM concentrations the fall velocity is lower, as expressed by Eq. 6. The same approach is used to express how SPM in the deep-water compartment $\left(\mathrm{SPM}_{\mathrm{DW}}\right)$ would influence aggregation and the settling velocity.

4. The turbulence of the water is very important for the fall velocity of suspended particles (Burban et al. 1989, 1990). Generally, there is more turbulence, which keeps the particles suspended, and hence causes lower settling rates, in the surface water than in the deep-water compartment. The turbulence in the surface water is also generally greater in large and shallow systems (with high dynamic ratios, DR; see Fig. 10) compared to small and deep lakes. In this modelling, two dimensionless moderators $\left(Y_{\mathrm{DR}}\right.$ and $Y_{\mathrm{TDW}}$; see Fig. 12) related to the theoretical deep-water retention time and the dynamic ratio have been used to quantify how turbulence is likely to influence the settling velocity in the surface-water and deep-water compartments. The dimensionless 
Fig. 12 The sub-model illustrating the calculation routines to estimate the influence of turbulence on sedimentation in deep-water areas
Sub-model for the influence of deep water turbulence on sedimentation

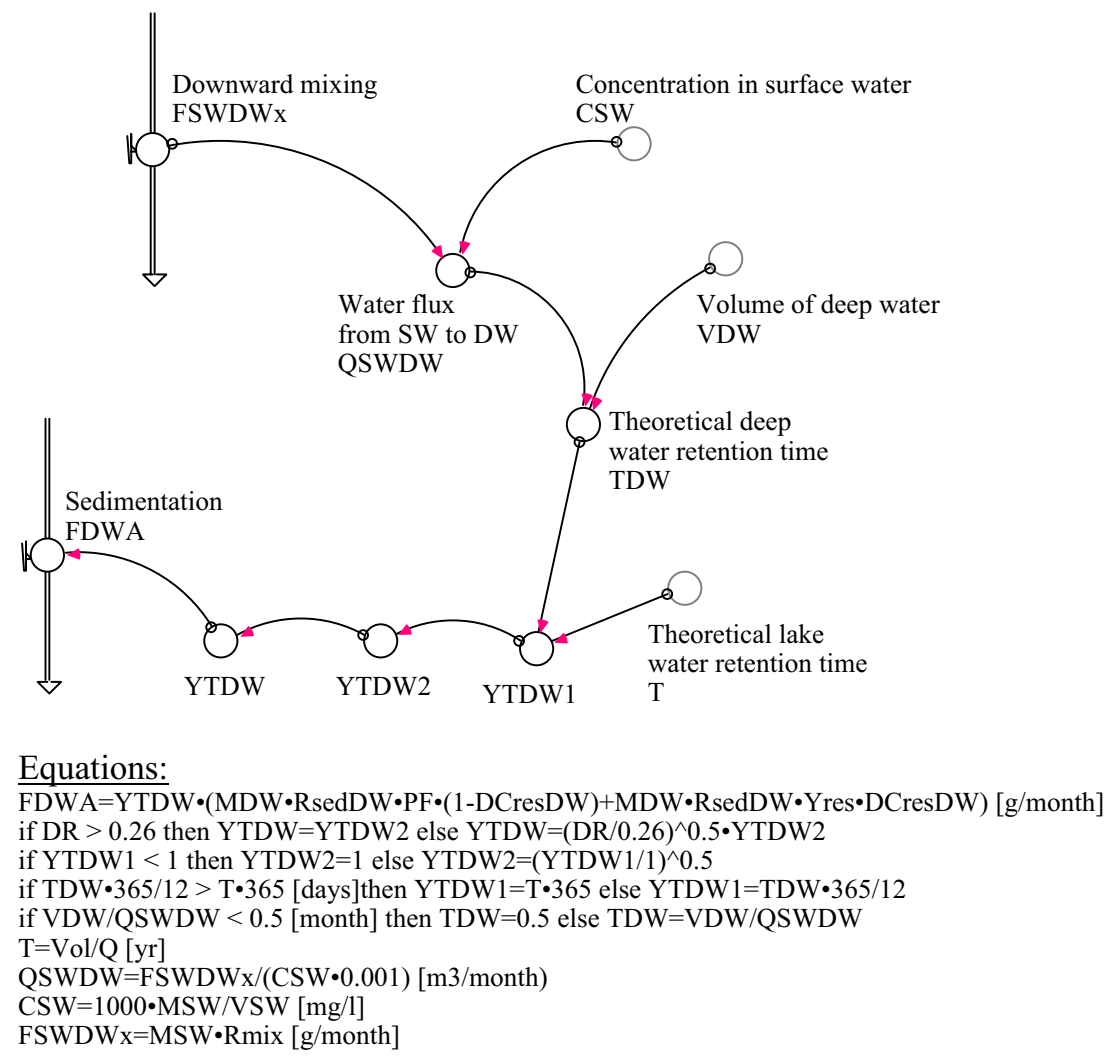

moderator for the dynamic ratio (the potential turbulence in the lake), $Y_{\mathrm{DR}}$, is given by:

$$
\text { If } \begin{aligned}
D R<0.26 \text { then } Y_{D R} & =D R / 0.26 \\
\text { else } Y_{D R} & =0.26 / D R
\end{aligned}
$$

Systems with a DR value of 0.26 (see Fig. 10) are likely to have a minimum of ET areas (15\% of the area) and the higher the DR value, the larger the area relative to the mean depth and the higher the potential turbulence and the lower the settling velocity. The potential turbulence in the deep water is smaller than in the surface water, and hence the fall velocity faster. This is quantified in the following manner (see also Fig. 12):

- The turbulence in the deep water is related to the smallest value (the fastest water exchange) of either the theoretical lake water retention time $(T)$ or the theoretical deep water retention time $\left(T_{\mathrm{DW}}\right)$ and to the morphometry of the lake, as given by the dynamic ratio (DR). If the dynamic ratio is $<0.26$, the influence of turbulence on the settling velocity is the deep water is reduced by a factor $\sqrt{ }(\mathrm{DR} / 0.26)$, if all else is constant.

- If the smallest value of $T$ or $T_{\mathrm{DW}}$ is $<1$ day, this is a boundary condition $\left(Y_{\mathrm{TDW}}=1\right)$; if the smallest value is longer than 1 day, the dimensionless moderator is given by if $\sqrt{ }\left(Y_{\mathrm{TDW}} / 1\right)$. For example, if the smallest value of $T$ or $T_{\mathrm{DW}}$ is 113 days (as for Mirror Lake), $\sqrt{ }\left(Y_{\mathrm{TDW}} / 1\right)$ is 11 ; and given the fact that DR for this lake is 0.067 , the settling velocity in the deep-water zone is a factor of 5.5 higher than we would have had without the two dimensionless moderators $Y_{\mathrm{DR}}$ and $Y_{\mathrm{TDW}}$.

5. The fraction of resuspended matter $\left(\mathrm{DC}_{\mathrm{res}}\right)$. The resuspended particles have already been aggregated, they have also generally been influenced by benthic activities, which will create a "gluing effect", and they have a comparatively short distance to fall after being resuspended (Håkanson and Jansson 1983). The longer the particles have stayed on the bottom, the larger the potential 
gluing effect and the faster the settling velocity if the particles are resuspended. The resuspended fraction of TP in the surface water is calculated by means of the distribution coefficient ( $\left.\mathrm{DC}_{\text {ressw }}\right)$, which is defined by the ratio between resuspension from ET areas to surface water (SW) relative to all fluxes to the surface-water compartment:

$D C_{\text {resSW }}=F_{E T S W} /\left(F_{E T S W}+F_{\text {prec }}+F_{\text {in }}+F_{D W S W x}\right)$

$F_{\text {ETSW }}$

resuspension from ET areas to surface-water areas (g TP/month)

$F_{\text {prec }} \quad$ inflow of TP from direct precipitation (g TP/ month)

$F_{\text {in }} \quad$ inflow of TP from tributaries (g TP/month)

$F_{\text {Dwswx }}$ upward mixing (g TP/month)

$\mathrm{DC}_{\mathrm{resSW}}$ is calculated automatically in the model. The dimensionless moderator expressing how much faster resuspended particles settle compared to primary particles is given by:

$Y_{\text {res }}=\left(\left(T_{E T} / 1\right)+10\right)$

where $T_{\mathrm{ET}}$ is the mean retention time (the mean age in months; 1 month is a reference value) of the particles on ET areas in months, as estimated from the dynamic ratio (DR) in the following way:

$$
\text { If } \begin{aligned}
D R<0.26 \text { then } T_{E T} & =Y_{D R 1}=12 \cdot(D R / 0.26) \\
\text { else } T_{E T} & =12 \cdot(0.26 / D R)
\end{aligned}
$$

This gives $Y_{\text {res }}=14.6,22,13.1$ and 11.2 (months) for lakes with DR values of $0.1,0.26,1$ and 2.6.

The resuspended fraction of TP in the deep-water compartment is calculated from:

$$
\begin{aligned}
D C_{\text {res } D W}= & F_{E T D W} \\
& /\left(F_{E T D W}+F_{S W D W}+F_{A D W}+F_{S W D W x}\right)
\end{aligned}
$$

$F_{\text {ETDW }}$ resuspension from ET areas to deep-water areas (g TP/month)

$F_{\text {SwDw }}$ sedimentation, i.e., transport from surface water to deep-water areas (g TP/month)

$F_{\text {ADW }}$ diffusive transport from A-sediments (gTP/ month)

$F_{\text {SwDWx }}$ downward mixing (g TP/month)
Also $\mathrm{DC}_{\text {resDW }}$ is calculated automatically in the model. Sedimentation from the surface-water com-

\begin{tabular}{|c|c|}
\hline$M_{\mathrm{SW}}$ & $\begin{array}{l}\text { the total mass of TP in the surface-water } \\
\text { compartment }(\mathrm{g})\end{array}$ \\
\hline$v_{\text {def }}$ & $\begin{array}{l}\text { the default settling velocity settling }(=6 \mathrm{~m} / \\
\text { month) }\end{array}$ \\
\hline$D_{\mathrm{ET}}$ & $\begin{array}{l}\text { the average depth of the surface-water } \\
\text { compartment }(\mathrm{m})\end{array}$ \\
\hline $\mathrm{PF}$ & $\begin{array}{l}\text { the particulate fraction of } \mathrm{TP}(\mathrm{PF}=\mathrm{PP} / \mathrm{TP}= \\
0.56 \text {, see Fig. } 8)\end{array}$ \\
\hline ET & $\begin{array}{l}\text { the fraction of } \mathrm{ET} \text { areas }\left(\mathrm{ET}=\mathrm{Area}_{\mathrm{ET}} / \mathrm{Area}\right) \text {, } \\
\text { which is estimated by a sub-model given in } \\
\text { Eq. } 3\end{array}$ \\
\hline$Y_{\mathrm{DR}}$ & $\begin{array}{l}\text { the dimensionless moderator expressing } \\
\text { how changes in dynamic ratio (turbulence) } \\
\text { would influence the settling velocity (Eq. 6) }\end{array}$ \\
\hline$Y_{\text {SPMSW }}$ & $\begin{array}{l}\text { the dimensionless moderator for how } \\
\text { variations in SPM in the surface water } \\
\text { influence the settling velocity (Eq. } 5 \text { ) }\end{array}$ \\
\hline $\mathrm{DC}_{\mathrm{resSW}}$ & $\begin{array}{l}\text { The distribution coefficient for the } \\
\text { resuspended fraction in the surface water } \\
\text { (Eq. } 7 \text { ) }\end{array}$ \\
\hline$Y_{\text {res }}$ & $\begin{array}{l}\text { the dimensionless moderator for how much } \\
\text { faster the resuspended fraction settles out } \\
\text { compared to the primary materials related } \\
\text { to the age of the resuspendable ET } \\
\text { sediments (Eq. } 8 \text { ) }\end{array}$ \\
\hline
\end{tabular}
partment $(\mathrm{SW})$ to the ET areas $\left(\mathrm{F}_{\mathrm{SWET}}\right)$ is given by:

$$
\begin{aligned}
F_{S W E T}= & M_{S W} \cdot\left(v_{d e f} / D_{E T}\right) \cdot P F \cdot E T \cdot Y_{D R} \cdot \\
& Y_{S P M S W}\left(\left(1-D C_{r e s S W}\right)+Y_{\text {res }} \cdot D C_{\text {resSW }}\right)
\end{aligned}
$$

One should note, that the basic sedimentation rates for surface water and deep-water areas may be written as $R_{\mathrm{SW}}=v_{\mathrm{SW}} / D_{\mathrm{Sw}}$ and $R_{\mathrm{DW}}=v_{\mathrm{DW}} / D_{\mathrm{DW}}$. The mean depths of the surface and deep-water areas, $D_{\mathrm{SW}}$ and $D_{\mathrm{DW}}$, are calculated from equations given in Fig. 13.

Sedimentation from the surface water (SW) to the deep water (DW; $F_{\text {SWDW }}$ ) is calculated in the same way as:

$$
\begin{aligned}
F_{S W D W}= & M_{S W} \cdot\left(v_{d e f} / D_{A}\right) \cdot P F \cdot E T \cdot Y_{D R} \cdot Y_{S P M D W} \\
& \left(\left(1-D C_{r e s D W}\right)+Y_{r e s} \cdot D C_{r e s D W}\right)
\end{aligned}
$$


Fig. 13 The sub-model to calculate the theoretical wave base separating $\mathrm{T}$ areas and $\mathrm{A}$ areas $\left(D_{\mathrm{WB}}\right)$, the area above $D_{\mathrm{WB}}$ (the ET areas), the area below $D_{\mathrm{WB}}$ (the A areas); operational boundary conditions and algorithms

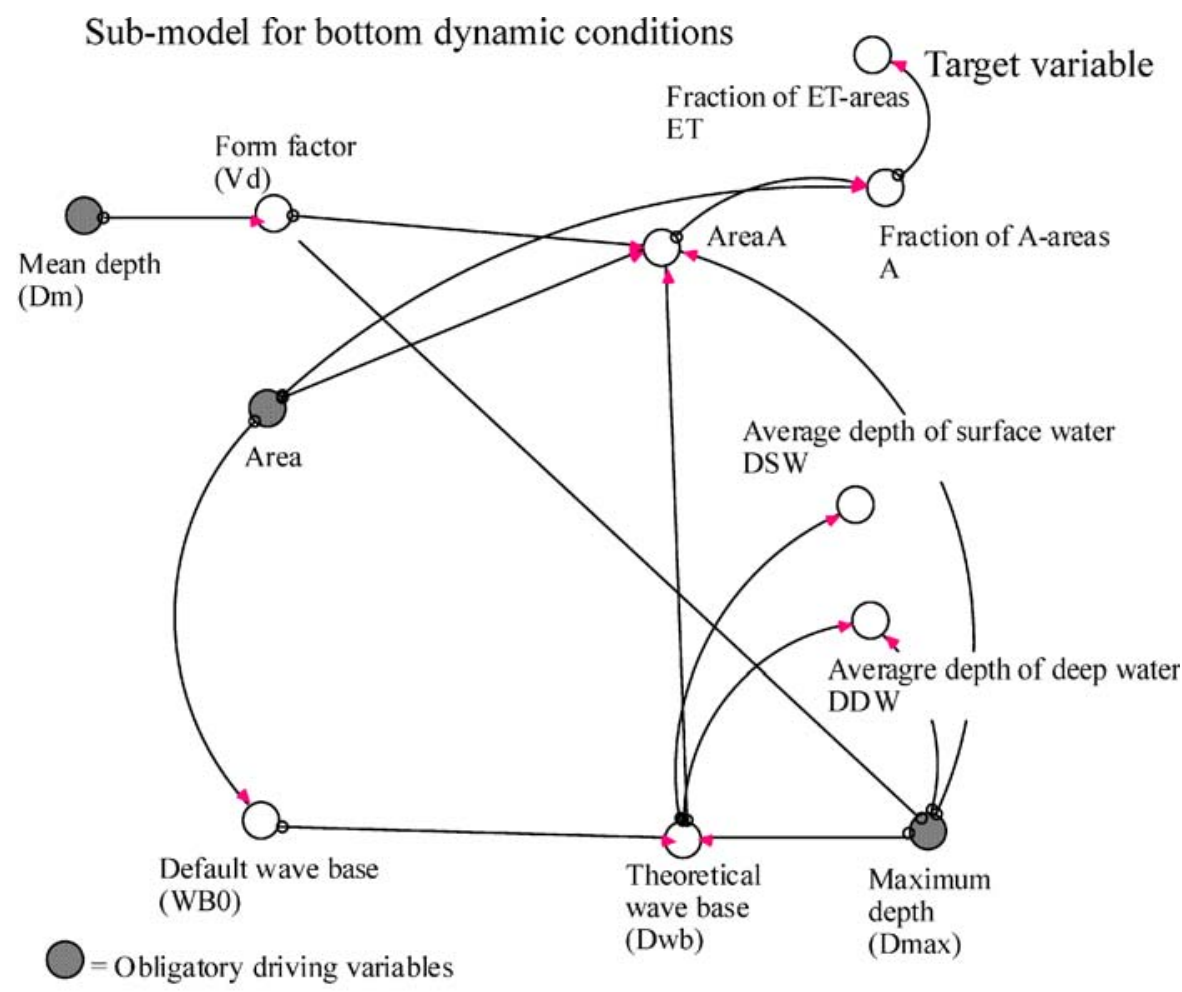

\section{Equations:}

$\mathrm{A}=$ AreaA $/$ Area

Area $A=\operatorname{Area} \cdot\left((\text { Dmax-Dwb }) /\left(\operatorname{Dmax}+\operatorname{Dwb} \cdot \operatorname{EXP}\left(3-\mathrm{Vd}^{\wedge} 1.5\right)\right)\right)^{\wedge}(0.5 / \mathrm{Vd})$

$\mathrm{DDW}=$ if $($ Dmax-Dwb $) / 2<1$ then 1 else $($ Dmax-Dwb $) / 2$

$\mathrm{DSW}=\mathrm{Dwb} / 2$

$\mathrm{ET}=(1-\mathrm{A})$

$\mathrm{WB} 0=\left(45.7 \cdot\left(\text { Area } 10^{\wedge}(-6)\right)^{\wedge} 0.5 /\left(21.4+\left(\text { Area } \cdot 10^{\wedge}(-6)\right)^{\wedge} 0.5\right)\right)$

If WB0 $>0.95 \cdot$ Dmax then Dwb $=0.95 \cdot$ Dmax else Dwb

$\mathrm{Vd}=3 \cdot \mathrm{Dm} / \mathrm{Dmax}$
And sedimentation from deep water to accumulation areas as:

$$
\begin{aligned}
F_{D W A}= & M_{D W} \cdot\left(v_{d e f} / D_{A}\right) \cdot P F \cdot Y_{D R} \cdot Y_{S P M D W} \cdot Y_{T D W} \\
& \cdot\left(\left(1-D C_{r e s D W}\right)+Y_{r e s} \cdot D C_{r e s D W}\right)
\end{aligned}
$$

$M_{\text {DW }} \quad$ the total mass of TP in the deep-water compartment $(\mathrm{g})$

$D_{\mathrm{A}} \quad$ the average depth of the deep-water compartment (m)

$Y_{\text {SPMDW }}$ the dimensionless moderator for how variations in SPM in the deep water influence the settling velocity

$\mathrm{DC}_{\mathrm{resDw}}$ the distribution coefficient for the resuspended fraction in the deep water (Eq. 10)
$Y_{\text {TDW }}$ the dimensionless moderator for how turbulence in the deep water influences sedimentation (Fig. 12)

\section{Resuspension}

By definition, the materials settling on ET areas will not stay permanently where they were deposited but will be resuspended by wind/wave activity. If the age of the material $\left(T_{\mathrm{ET}}\right)$ is set to a very long period, e.g., 10 years, these areas will function as accumulation areas; if the age is set to 1 week or less, they will act as erosion areas. In this modelling, it is assumed that the mean age of these deposits are estimated by Eq. 8. Resuspension back into surface water, $F_{\text {ETSW, }}$ 
i.e., mostly wind/wave-driven advective fluxes, is given by:

$F_{E T S W}=\left(M_{E T} \cdot(1-V d / 3)\right) / T_{E T}$

Resuspension to deep-water areas, $F_{\text {ETSw, by: }}$

$F_{E T D W}=\left(M_{E T} \cdot(V d / 3)\right) / T_{E T}$

$M_{\mathrm{ET}}$ the total amount of resuspendable TP on ET areas $(\mathrm{g})$

$\mathrm{Vd}$ the form factor; note that $\mathrm{Vd} / 3$ is used as a distribution coefficient to regulate how much of the resuspended material from ET areas that will go the surface water or to the deep-water compartment. If the lake is U-shaped, $\mathrm{Vd}$ is about 3 (i.e., $D_{\max } \approx D_{\mathrm{m}}$ ) and all resuspended TP from ET areas will flow to the deep-water areas. If, on the other hand, the lake is shallow and $\mathrm{Vd}$ is small, most resuspended matter will flow to the surface-water compartment

$T_{\mathrm{ET}} \quad$ the age of TP on ET areas (see Eq. 9)

\section{Diffusion}

Diffusion of phosphorus from A areas back to deep water $\left(F_{\mathrm{ADW}}\right.$ in grams TP per month) is given by (see also Fig. 14):

$$
F_{A W}=M_{A} \cdot R_{\text {diffo }} \cdot Y_{\text {sed }} \cdot Y_{T P A} \cdot Y_{T D W} \cdot Y_{D R \operatorname{diff}} \bullet(D W T / 4)
$$

Where $M_{\mathrm{A}}$ is total mass of TP in the accumulation area sediments (g), DWT the deep-water temperature $\left({ }^{\circ} \mathrm{C}\right)$ and the default diffusion rate $\left(R_{\text {diffo }}\right)$ is 0.0003 (1/year; Håkanson 1999). The default value is influenced by several dimensionless moderators influencing diffusion of phosphorus; basically, diffusion is calculated from sedimentation of particulate $P$, recalculated into sedimentation of organic material and the potential supply of oxygen calculated from the theoretical deep-water retention time $\left(T_{\mathrm{DW}}\right)$ and the dynamic ratio (DR).

Sedimentation of particulate TP on A areas $\left(F_{\text {DWA }}\right.$ in grams TP per month) is calculated automatically in the model and recalculated into sedimentation of organic matter $\left(\operatorname{Sed}_{\mathrm{A}}\right.$ in micrograms per squared centimeters $\left.\cdot d\right)$ assuming that the TP concentration of SPM is $2 \mathrm{mg} / \mathrm{g}$ dw (Håkanson 2006).

$\operatorname{Sed}_{A}=F_{D W A} \cdot 10^{5} /(30 \cdot 2 \cdot A)$

The higher $\mathrm{Sed}_{\mathrm{A}}$, the more oxygen consuming organic matter deposited on A areas, the lower the oxygen concentration and the higher the diffusion of phosphorus. This is calculated by:

$$
\text { If } \begin{aligned}
\operatorname{Sed}_{A} & <50\left(\mu \mathrm{g} / \mathrm{cm}^{2} \cdot d\right) \text { then } Y_{\text {sed }} \\
& =(2-1 \cdot(G S / 50-1)) \text { else } Y_{\text {sed }} \\
& =(2+A m p \cdot(G S / 50-1))
\end{aligned}
$$

Where $Y_{\text {sed }}$ is the dimensionless moderator for sedimentation in the algorithm for diffusion. The value 50 is a boundary condition; if $\operatorname{Sed}_{\mathrm{A}}$ is lower than that, the risks of high diffusion would be small. This diffusion algorithm accounts not just for the monthly sedimentation, but for the long-term sedimentation. This is calculated using a smoothing function with an average time of 5 years (60 months; see Håkanson 1999, for more information on smoothing functions). So, $\mathrm{Sed}_{\mathrm{A}}$ is transformed into gross sedimentation (GS; the long-time average sedimentation given in micrograms per squared centimeters $\cdot d$ ) by the following smoothing function: $\mathrm{GS}=\mathrm{SMTH}$ $\left(\operatorname{Sed}_{\mathrm{A}}, 60, \operatorname{Sed}_{\mathrm{A}}\right)$. The amplitude value (Amp), which expresses how diffusion should change with a change in GS, is defined by:

$A m p=\left(C_{A} / 2\right) \cdot 50$

$C_{\mathrm{A}}$ is the TP concentration in surficial $(0-10 \mathrm{~cm}) \mathrm{A}$ sediments. This means that if $C_{\mathrm{A}}$ becomes higher than $2 \mathrm{mg} / \mathrm{g} \mathrm{dw}$, the amplitude value will increase and hence also the diffusion. This is one boundary condition related to TP concentration in A sediments. The other boundary condition is given by $Y_{\mathrm{TPA}}$, which is defined by:

$$
\begin{aligned}
\text { If } C_{A}<0.5(\mathrm{mg} / \mathrm{gdw}) \text { then } Y_{T P A} & =0 \\
\text { else } Y_{T P A} & =\left(C_{A}-0.5\right)
\end{aligned}
$$

This means that if $C_{\mathrm{A}}$ approaches 0.5 , diffusion of TP from sediments will also approach zero because 
Fig. 14 Illustration of submodels and equations for diffusion, bioturbation, sedimentation, burial and age of accumulation area sediments

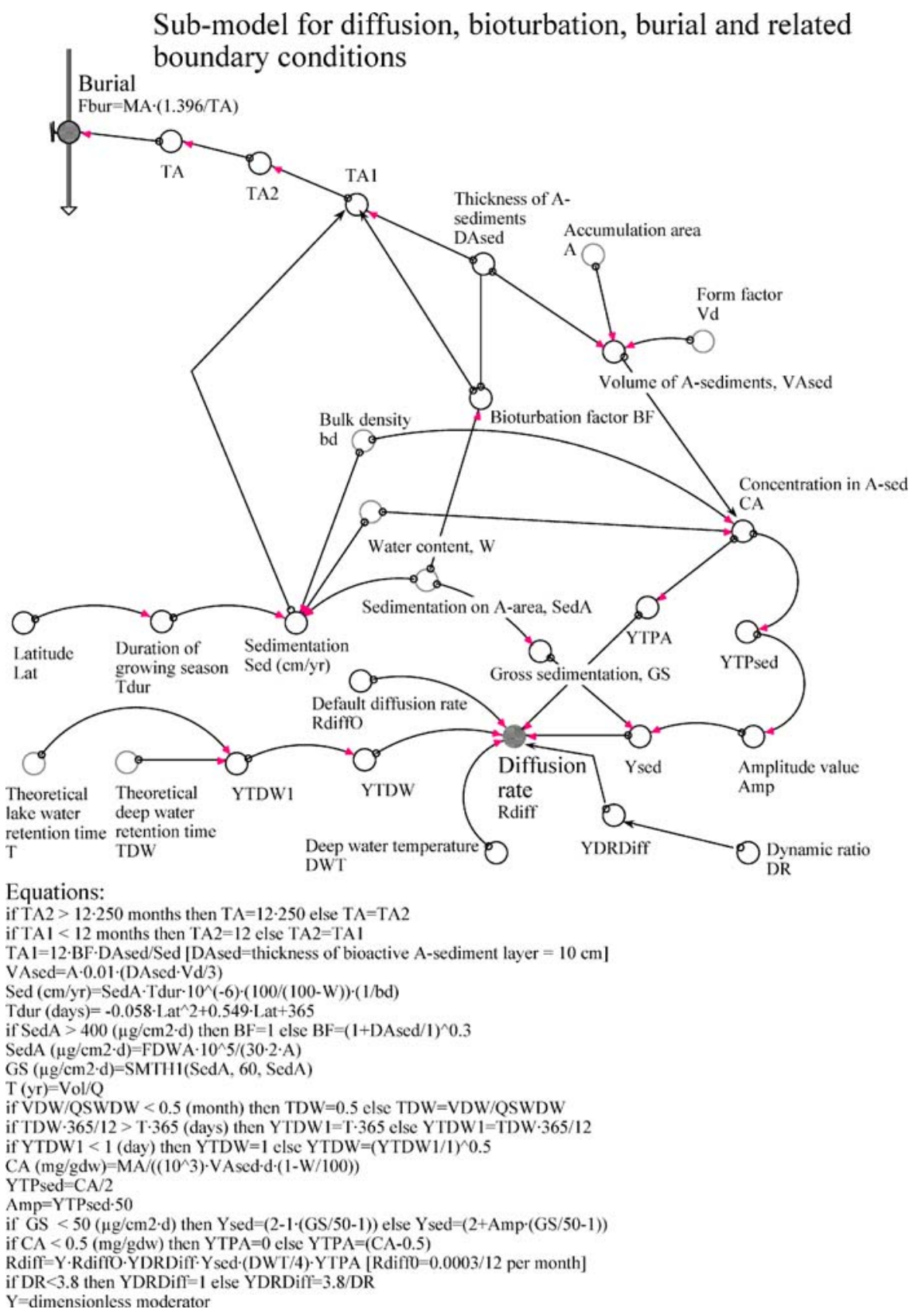

all TP should not be subject to diffusion; $C_{\mathrm{A}}$ generally varies between 0.5 and $2 \mathrm{mg} / \mathrm{g}$ dw in top $10 \mathrm{~cm}$ A sediments in lakes (Håkanson and Jansson 1983), and this information is used in this algorithm for diffusion.

The next moderator in Eq. 16 relates to the deepwater renewal. The shortest value of $T$ (the theoretical lake water retention time) and $T_{\mathrm{DW}}$ (the theoretical deep water retention time) is used in this algorithm to express the water and oxygen renewal of the deepwater compartment.

$$
\text { If } \begin{aligned}
& T_{D W} \cdot 365 / 12>T \cdot 365 \text { then } Y_{T D W 1} \\
& =T \cdot 365 \text { else } Y_{T D W 1} \\
& =T_{D W} \cdot 365 / 12 \text { if } Y_{T D W 1}<1 \text { then } Y_{T D W} \\
& =1 \text { else } Y_{T D W}=\sqrt{ }\left(Y_{T D W 1} / 1\right)
\end{aligned}
$$


If the value is lower than 1 day, this is a boundary condition for the dimensionless moderator $\left(Y_{\text {TDW }}\right)$ and if the value gives a longer water retention time, the impact on the diffusion rate is given by $\sqrt{ }\left(Y_{\mathrm{TDW} 1} /\right.$ 1). So, if $T$ or $T_{\mathrm{DW}}$ is 120 days (circulation twice a year), $Y_{\mathrm{TDW}}$ is 11 and the diffusion rate 11 times higher than if $T$ or $T_{\mathrm{DW}}$ is 1 day.

The next dimensionless moderator influencing diffusion in Eq. 16, $Y_{\text {DRDiff, }}$ also relates to oxygenation. If the lake is shallow and dominated by resuspension processes, i.e., if the dynamic ratio (DR) is higher than 3.8 (see Fig. 10), one should expect that the A sediments are rather well oxygenated; the higher the DR value above 3.8, the lower the potential diffusion. This is given by:

$$
\begin{aligned}
& \text { If } D R<3.8 \text { then } Y_{\text {DRDiff }}=1 \text { else } Y_{\text {DRDiff }} \\
& =3.8 / D R
\end{aligned}
$$

The last dimensionless moderator in Eq. 16 is the ratio between the actual deep-water temperature and a reference temperature of $4^{\circ} \mathrm{C}$, i.e., (DWT/4); the higher the actual deep-water temperature (DWT), the higher the bacterial decomposition, the lower the oxygen concentration and the higher the diffusion of phosphorus.

This means that in highly productive but shallow lakes with frequent resuspensions, and in low-productive deep lakes, with little sedimentation, diffusion of phosphorus from the A sediments should be relatively low, and for lakes in-between these limits, diffusion could be very important for the actual TP concentrations in lake water, especially in relatively deep and eutrophic systems.

\section{Burial}

If the sediments are oxic (i.e., when the bioturbation is likely high), the age of the A sediments $\left(T_{\mathrm{A}}\right)$ and hence burial $\left(F_{\text {bur }}\right)$, i.e., the transport from surficial $(0-10 \mathrm{~cm})$ A sediments to deeper sediment layer, will be influenced by the biological mixing of zoobenthos (Håkanson and Jansson 1983). We have: If $\operatorname{Sed}_{\mathrm{A}}>400$ $\left(\mu \mathrm{g} / \mathrm{cm}^{2} \cdot \mathrm{d}\right.$; which is a boundary value for eutrophic systems; Håkanson and Boulion 2002) then

$B F=1$ else $B F=\left(1+D_{A S} / 1\right)^{0.3}$
$\mathrm{BF}$ is the bioturbation factor (dimensionless). If the sedimentation is higher than 400, the $\mathrm{O}_{2}$ concentration in the deep-water zone is likely lower than $0.2 \mathrm{mg} / \mathrm{l}$ during the summer period and then zoobenthos are likely to die and bioturbation halted. $D_{\mathrm{AS}}$ is the thickness of the bioactive A-sediment layer (in centimeters). The default value for $D_{\mathrm{AS}}$ is set to $10 \mathrm{~cm}$ (Håkanson and Jansson 1983). This means that $\left(1+D_{\mathrm{AS}} / 1\right)^{0.3}=2.05$ and the sediment likely 2.05 times older than calculated from the ratio between the depth of the active A sediments $\left(D_{\mathrm{AS}}\right.$ in $\left.\mathrm{cm}\right)$ and sedimentation (Sed in centimeters per year). Sedimentation, in turn is calculated as:

$$
\operatorname{Sed}=\operatorname{Sed}_{A} \cdot T_{d u r} \cdot 10^{-6} \cdot(100 /(100-W)) \cdot(1 / b d)
$$

Where $T_{\text {dur }}$ is the duration of the growing season in days calculated from latitude (Lat in ${ }^{\circ} \mathrm{N}$; from Håkanson and Boulion 2002) as:

$$
T_{d u r}=-0.058 \cdot \text { Lat }^{2}+0.549 \cdot \text { Lat }+365
$$

The water content (W), bulk density (bd) and also the organic content (=loss on ignition, IG) of the A sediments are estimated according to Fig. 15 (see also Table 4; from Håkanson and Boulion 2002). In LakeMab, we have also included simple estimations of the initial water content, which is calculated from the dynamic ratio as:

$$
\begin{aligned}
\text { If } D R & >6 \text { then } W=65(\% w w) \text { else if } D R \\
& >0.5 \text { then } W=75 \text { else if } D R \\
& >0.045 \text { then } W=85 \text { else } W=95
\end{aligned}
$$

This means that shallow lakes dominated by resuspension (if $\mathrm{DR}>6$ ), $\mathrm{W}$ is likely low (65\%); very deep lakes with $\mathrm{DR}<0.045$, on the other hand, are estimated to have very loose A sediments $(W=95)$. Lakes in-between these DR limits are likely to have A sediments with $W$ values of 75 or $85 \%$, as given by Eq. 32. The organic content of the A sediments (IG in percent $\mathrm{dw}$ ) is needed to calculated the bulk density (bd in grams per cubic centimeter), which is needed to calculate the volume of A sediments (in cubic meter), 


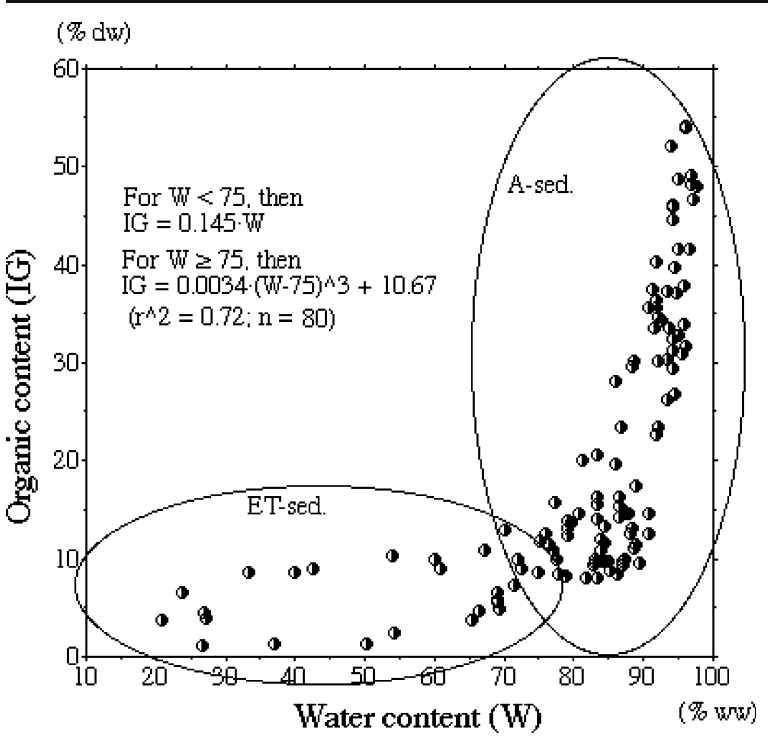

Fig. 15 The relationship between the sediment water content ( $W$; using data from A areas) and the sediment organic content (loss on ignition, also using data from A areas). Data from Håkanson and Boulion (2002)

which is needed to calculate diffusion of phosphorus from A sediments. IG is estimated from:

If $W>75(\% w w)$ then $I G$

$$
\begin{aligned}
& =\left(1,280+(W-75)^{3}\right) / 207 \text { else } I G \\
& =W / 11.9
\end{aligned}
$$

The bulk density (bd) is calculated from IG (IG* in percent ww) and $W$ from a standard formula (from Håkanson and Jansson 1983) as:

$b d=100 \cdot 2.6 /(100+(W+I G \cdot(1-W / 100)) \cdot(2.6-1))$

Burial $\left(F_{\text {bur }}\right)$ is then given by (see also Fig. 14):

$F_{\text {bur }}=M_{A} \cdot 1.396 / T_{A}$

Where $M_{\mathrm{A}}$ is the total amount of $\mathrm{TP}$ in $\mathrm{A}$ sediments $(\mathrm{g}), T_{\mathrm{A}}$ is the age of the active A sediments and 1.396 is the halflife constant (Håkanson and Peters 1995). We have set the boundary conditions for $T_{\mathrm{A}}$ in the following manner. Basically, there are is a lower limit for $T_{\mathrm{A}}$ of 1 year and an upper limit of 250 years when TP can escape from the A sediments by diffusion.

$T_{A}=12 \cdot B F \cdot D_{A S} / \mathrm{Sed}$

$$
\text { If } \begin{aligned}
T_{A} & <12(\text { months }) \text { then } T_{A 1}=12 \text { else } T_{A 1} \\
& =T_{A} \text { If } T_{A 1}>12 \cdot 250 \text { then } T_{A 2} \\
& =12 \cdot 250 \text { else } T_{A 2}=T_{A 1}
\end{aligned}
$$

The bioturbation factor (BF) is defined by Eq. 23, the default value for the depth of the bioactive $A$ sediments, $D_{\mathrm{AS}}$ is set to $10 \mathrm{~cm}$ and the sedimentation (Sed in centimeters per year) is calculated from sedimentation $\left(\operatorname{Sed}_{\mathrm{A}}\right.$ in $\left.\mu \mathrm{g} / \mathrm{cm}^{2} \cdot \mathrm{d}\right)$.

Outflow, Mixing and Stratification

If the water depth that separates the surface water and the deep-water compartments, the theoretical wave base, is defined in a relevant way, this will also imply that outflow from the lake $\left(F_{\text {out }}\right)$ can be calculated in a simple, operational and mechanistic manner. The outflow ( $F_{\text {out }}$ in $\mathrm{g} \mathrm{TP} /$ month) is given by:

$F_{\text {out }}=M_{S W} \cdot Y_{Q} \cdot Y_{\text {evap }} \cdot Y_{\text {prec }} /(12 \cdot T)$

$M_{\mathrm{SW}}$ the amount of TP in the surface-water compartment $(\mathrm{g})$

$Y_{\mathrm{Q}} \quad$ the dimensionless moderator for the monthly water transport out of the lake (from the $Q$ model, as previously discussed)

$Y_{\text {evap }}$ The dimensionless moderator for evaporation; from Håkanson (2000); if $S W T<9^{\circ} C$ then $Y_{\text {evap }}=1$ else $Y_{\text {evap }}=(1-0.4 \cdot(S W T / 9-1))$; SWT is the surface-water temperature in ${ }^{\circ} \mathrm{C}$ from the temperature sub-model; the higher SWT, the higher the evaporation and the lower the outflow of water from the lake

$Y_{\text {prec }}$ the dimensionless moderator for precipitation; from Håkanson (2000); if Prec $<650 \mathrm{~mm} /$ year then $Y_{\text {prec }}=(1+1.8 \cdot($ Prec $/ 650-1)$ else $Y_{\text {prec }}=(1+0.5 \cdot($ Prec $/ 650-1))$; the lower Prec, the lower the outflow of water from the lake

$T$ the theoretical surface water retention time (month); defined traditionally by $\mathrm{Vol} / Q$

The mixing between surface water and deep water depends on the stratification, which in turn depends on many climatological factors (prevailing winds, 
season of the year, etc.). The following sub-model for mixing first gives the monthly mixing rate $\left(R_{\text {mix }} ; 1 /\right.$ month) as a function of the absolute difference between mean monthly surface and deep-water temperatures.

$$
\text { If } \begin{aligned}
A B S(S W T-D W T)<4\left({ }^{\circ} C\right) \text { then } R_{\text {mix } 1} \\
=1 \text { else } R_{\text {mix } 1}=1 / A B S(S W T-D W T)
\end{aligned}
$$

That is, if the absolute difference between surface water (SWT) and deep-water temperatures (DWT) is smaller than $4^{\circ} \mathrm{C}$, it is assumed that the system is not stratified and $R_{\text {mix } 1}$ is set to 1 . We have defined the following boundary condition for mixing (see also Fig. 16). If MAET (mean annual surface water temperature; from the temperature sub-model) $>17^{\circ} \mathrm{C}$ or MAET $<4$ then $R_{\text {mix }}=1$ else $R_{\text {mix }}=R_{\text {mix } 1}$. The lake is not likely stratified if the dynamic ratio (DR) is higher than 3.8 (see Fig. 10). Then, the system is probably not dimictic but polymictic. A boundary condition for this is added to the model: If DR $>3.8$ then $R_{\text {mix }}=1$.
Fig. 16 The sub-model for upward and downward mixing

\section{Sub-model for mixing}

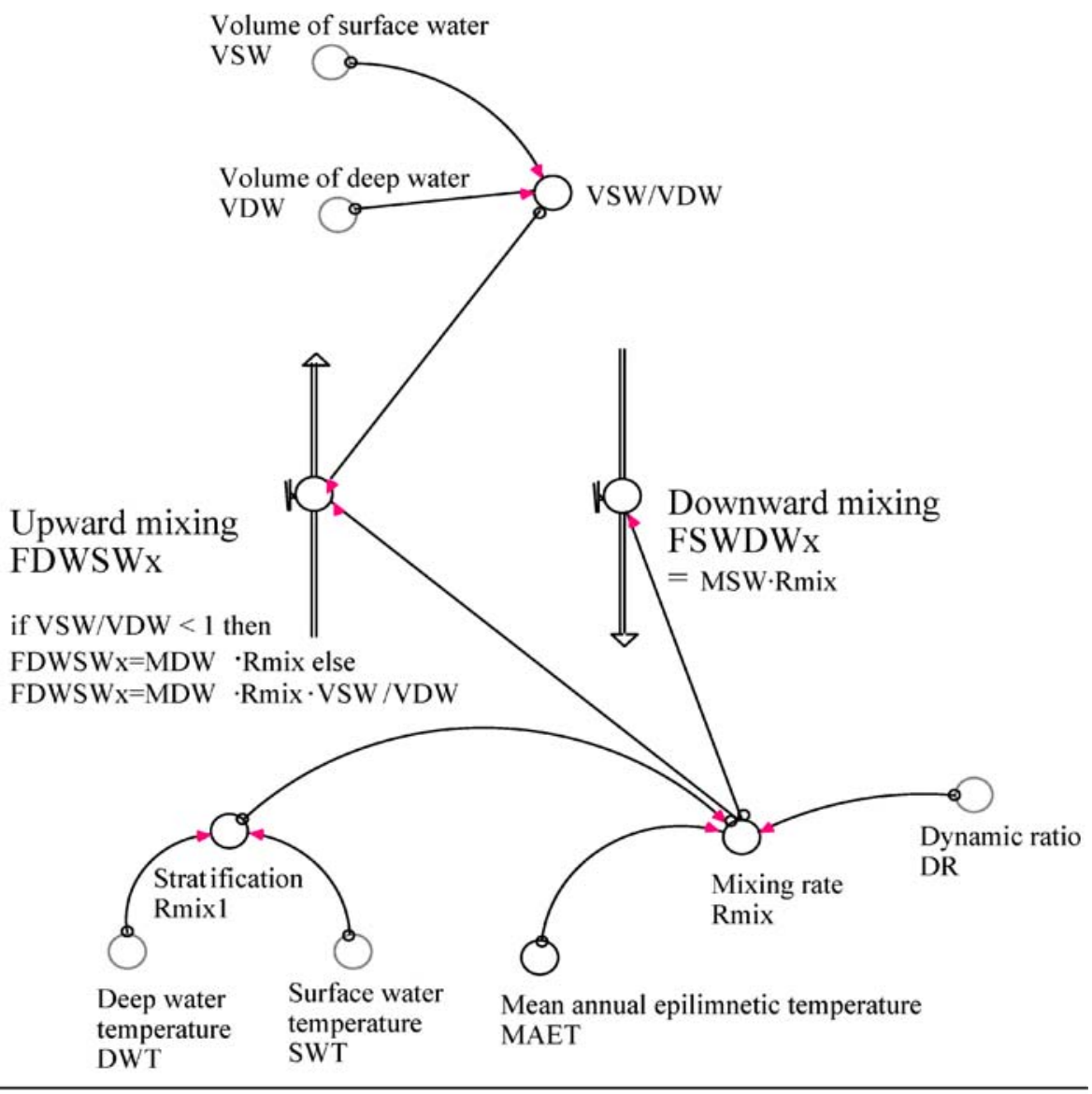

if $\mathrm{ABS}(\mathrm{SWT}-\mathrm{DWT})<4$ then Rmix $1=1$ else Rmix1=1/ABS(SWT-DWT)

if $\mathrm{MAET}>17{ }^{\circ} \mathrm{C}$ or DR $>3.8$ or MAET $<4{ }^{\circ} \mathrm{C}$ then $\mathrm{Rmix}=1$ else Rmix=Strat

$\mathrm{DR}=$ Area/Dm; [Area in $\mathrm{km} 2 ; \mathrm{Dm}$ in $\mathrm{m}$ ]

$\mathrm{MSW}=$ mass is surface water

MDW $=$ mass in deep water

$\mathrm{VSW}=($ Area $\cdot \mathrm{Dm}-\mathrm{A} \cdot \mathrm{Vd} \cdot($ Dmax-Dwb $) / 3)$

$\mathrm{VDW}=(\mathrm{Vol}-\mathrm{VSW})$

If $\mathrm{V} / \mathrm{SW} / \mathrm{VDW}>30$ then 30 else $\mathrm{VSW} / \mathrm{VDW}$ 
The downward flux, i.e., mixing from surface water to deep water, is given by:

$$
\begin{aligned}
F_{S W D W x} & =M_{S W} \cdot R_{\text {mix }} \\
& =\left(M_{S W} / V_{S W}\right) \cdot\left(V_{S W} / T_{S W}\right) \\
& =C_{S W} \cdot Q_{\text {mix }}
\end{aligned}
$$

Where the TP concentration in surface water $\left(C_{\mathrm{SW}}\right)$ is equal to $M_{\mathrm{SW}} / V_{\mathrm{SW}}$ and the water flux related to mixing $\left(Q_{\text {mix }}\right)$ is equal to $V_{\mathrm{SW}} / T_{\mathrm{SW}}\left(T_{\mathrm{SW}}\right.$ is the theoretical surface-water retention time). The upward mixing is given by:

$$
\text { If } \begin{aligned}
& V_{S W} / V_{D W}<1 \text { then } F_{D W S W x} \\
& =M_{D W} \cdot R_{\text {mix }} \text { else } F_{D W S W x} \\
& =M_{D W} \cdot R_{\text {mix }} \cdot V_{S W} / V_{D W}
\end{aligned}
$$

If the wave base $\left(D_{\mathrm{wb}}\right)$ is very close to the maximum depth $\left(D_{\max }\right)$, and hence the deep-water volume very small and the ratio $V_{\mathrm{Sw}} / V_{\mathrm{DW}}$ very large, the flux from deep-water to surface water can be so large that it will become difficult to get stable solutions using, e.g., Euler's or Runge-Kutta's calculation routines. This means that the following boundary condition is used for mixing:

If $V_{S W} / V_{D W}>30$ then 30 else $V_{S W} / V_{D W}$

\section{References}

Abrahamsson, O. \& Håkanson, L. (1998). Modelling seasonal flow variability of European rivers. Ecological Modelling, 114, 49-58.

Ahlgren, I., Ramberg, A., Jansson, M., Lundgren, A., Lindström, K., Persson, G., et al. (1979). Lake metabolism - Studies and results at the Institute of Limnology in Uppsala. Archiv fuÉr Hydrobiologie Beihefte Ergebnisse der Limnologie, 13, 10-30.

Andersen, J. M., (1974). Nitrogen and phosphorus budgets and the role of sediments in six shallow Danish lakes. Archiv Für Hydrobiologie, 74, 528-550.

Anneville, O., Ginot, V., Druart, J. C., \& Angeli, N. (2002). Long-term study (1975-1998) of seasonal changes in the phytoplankton in Lake Geneva: A multi-table approach. Journal of Plankton Research, 24, 993-1008.

Bachmann, R. W., Hoyer, M. V., \& Canfield, D. E. (1999). The restoration of Lake Apopka in relation to alternative stable states. Hydrobiologia, 394, 219-232.
Barbieri, A., \& Simona, M. (2001). Trophic evolution of Lake Lugano related to external load reduction: Changes in phosphorus and nitrogen as well as oxygen balance and biological parameters lakes and reservoirs. Research and Management, 6, 37-47.

Bengtsson, L. (1978). Effects of sewage diversion in Lake Södra Bergundasjön. 1. Nitrogen and phosphorus budgets. Vatten, 1, 2-9.

Bernhardt, H., Clasen, J., Hoyer, O., \& Wilhelms, A, (1985). Oligotrophication in lakes by means of chemical nutrient removal from the tributaries, its demonstration with the Wahnbach Reservoir. Archiv fuÉr Hydrobiologie. Supplement, 70, 481-533.

Bierman, V. J. Jr. (1980). A comparison of models developed for phosphorus management in the Great Lakes. In C. Loehr, C. S. Martin, \& W. Rast (Eds.), Phosphorus management strategies for lakes (pp. 235-255.). Ann Arbor: Ann Arbor Science Publishers.

Boers, P. C. M., Cappenberg, Th. E., \& van Raaphorst, W. (Eds) (1993). Proceeding of the third international workshop on phosphorus in sediments. Hydrobiologia, 253, 376.

Boynton, W. R., Kemp, W. M., \& Keefe, C. W. (1982). A comparative analysis of nutrients and other factors influencing estuarine phytoplankton production. In Kennedy, V. S. (Ed.), Estuarine comparisons (pp. 69-90). London: Academic.

Brock, T. D. (1985). A eutrophic lake: Lake Mendota, Wisconsin (p. 308). New York: Springer.

Brock T. D., Lee D. R., Janes, D., \& Winek, D. (1982). Groundwater seepage as a nutrient source to a drainage lake: Lake Mendota, Wisconsin. Water Research, 16, 1255-1263.

Bryhn, A., Håkanson, L., \& Eklund, J. (2006). Variabilities and uncertainties in key coastal water variables as a basis for understanding changes and obtaining predictive power in modelling. Manuscript, Institute of Earth Science, Uppsala University.

Burban, P.-Y., Lick, W., \& Lick, J. (1989). The flocculation of fine-grained sediments in estuarine waters. Journal of Geophysical Research, 94, 8223-8330.

Burban, P.-Y., Xu, Y.-J., McNeiel, J. \& Lick, W. (1990). Settling speeds of flocs in fresh water and seawater. Journal of Geophysical Research, 95, 18213-18220.

Chapra, S. C. (1980). Application of the phosphorus loading concept to the Great Lakes. In C. Loehr, C. S. Martin, \& W. Rast (Eds.), Phosphorus management strategies for lakes (pp. 135-152). Ann Arbor: Ann Arbor Science Publishers.

Coveney, M. F., Lowe, E. F., Battoe, L. E., Marzolf, E. R., \& Conrow, R. (2005). Response of a eutrophic, shallow subtropical lake to reduced nutrient loading. Freshwater Biology, 50, 1718-1730.

Dahl, M., Wilson, D. I., \& Håkanson, L. (2006). A combined suspended particle and phosphorus water quality model: Application to Lake Vänern. Ecological Modelling, 190, 55-71.

Dillon, P. J., \& Molot, L. A. (1996). Long-term phosphorus budgets and an examination of a steady-state mass balance model for central Ontario Lakes. Water Research, 30, 2273-2280. 
Dillon P. J, \& Molot, L. A., (1997). Dissolved organic and inorganic carbon mass balances in central Ontario lakes. Biogeochemist, 36, 29-42.

Edmondson, W. T., \& Lehman, J. T. (1981). The effect of changes in the nutrient income on the condition of Lake Washington. Limnology and Oceanography, 26, 1-29.

Faafeng, B., \& Nilssen, J. P. (1981). A twenty-year study of eutrophication in a deep, soft-water lake. Verh. int. Verein. Limnol., 21, 380-392.

Haande, S., Oredalen, T. J., Brettum, P., Løvik, J. E., \& Mortensen, T. (2005). Monitoring of Lakes Gjersjøen and Kolbotnvannet with tributaries 1972-2004 with focus on results from the 2004 season. Niva report 5010-2005. Niva, Oslo, 109 pp. (in Norwegian).

Haberman, J., Pihu, E., \& Raukas, A. (2004). Võrtsjär (p.542). Tallinn: Estonian Encyclopedia Publishers.

Hamm, A. (1978). Nutrient load and nutrient balance of some subalpine lakes after sewage diversion. Verhandlungen der Internationale Vereinigung fiir Theoretische und Angewandte Limnologie, 20, 975-984.

Håkanson, L. (1995). Fish farming and environmental effects in lakes - New results motivate new criteria for evaluations [In Swedish: Fiskodling och miljöeffekter i sjöar - nya resultat motiverar nya bedömningsunderlag]. Vatten 51, Bloms Boktryckeri, Lund, 103 sid.

Håkanson, L. (1999). Water pollution - Methods and criteria to rank, model and remediate chemical threats to aquatic ecosystems (p.299). Leiden: Backhuys.

Håkanson, L. (2000). Modelling radiocesium in lakes and coastal areas - new approaches for ecosystem modellers. A textbook with Internet support (p. 215). Dordrecht: Kluwer.

Håkanson, L. (2006). Suspended particulate matter in lakes, rivers and marine systems (p. 319). New Jersey: The Blackburn.

Håkanson, L., Blenckner, T., \& Malmaeus, J. M. (2004). New, general methods to define the depth separating surface water from deep water, outflow and internal loading for mass-balance models for lakes. Ecological Modelling, $175,339-352$.

Håkanson, L., \& Boulion, V. (2002). The Lake Foodweb Modelling predation and abiotic/biotic interactions (p. 344). Leiden: Backhuys.

Håkanson, L., \& Jansson, M. (1983). Principles of lake sedimentology (p. 316). Berlin: Springer.

Håkanson, L., \& Lindgren, D. (2006). The CoastWeb-model, a foodweb model based on functional groups for coastal areas including a mass-balance model for phosphorus. Manuscript, Inst. of Earth Sci., Uppsala Univ.

Håkanson, L., \& Peters, R. H. (1995). Predictive limnology. Methods for predictive modelling (p.464). SPB Academic, Amsterdam.

Haslauer, J., Moog, O., \& Pum, M. (1984). The effect of sewage removal on lake water quality (Fuschlsee, Salzburg, Austria). Archiv Für Hydrobiolgie, 101, 113-134.

Holtan, H. (1978). Eutrophication of Lake Mjøsa in relation to the pollutional load. Verhandlungen der Internationale Vereinigung fiir Theoretische und Angewandte Limnologie, 20, 734-742.

Holtan, H. (1979). The Lake Mjøsa story. Archiv fuÉr Hydrobiologie Beihefte, 13, 242-258.
Jansson, M. (1978). Experimental lake fertilization in the Kuokkel area, northern Sweden: Budget calculations and the fate of nutrients. Verhandlungen der Internationale Vereinigung fiir Theoretische und Angewandte Limnologie, 20, 857-862.

Jeppesen E., Søndergaard M., Jensen J. P., et al. (2005). Lake responses to reduced nutrient loading - An analysis of contemporary long-term data from 35 case studies. Freshwater Biology, 50, 1747-1771.

Kjellberg, G. (2004). Management oriented monitoring of Lake Mjøsa with tributaries. Annual data report for 2003. NIVA report 4319-2004. NIVA, Oslo, 91 pp. (in Norwegian).

Kranck, K. (1973). Flocculation of suspended sediment in the sea. Nature, 246, 348-350.

Kranck, K. (1979). Particle matter grain-size characteristics and flocculation in a partially mixed estuary. Sedimentology, $28,107-114$

Kunimatsu, T., \& Kitamura, G. (1981). Phosphorus balance of Lake Biwa. Verhandlungen der Internationale Vereinigung fiir Theoretische und Angewandte Limnologie, 21, 539544.

Kvarnäs, H. (2001). Morphometry and hydrology of the four large lakes of Sweden. Ambio, 30, 467-474.

Lathrop, R. C., Carpenter, S. R., Stow, C. A., Soranno, P. A., \& Panuska, J. C. (1998). Phosphorus loading reductions needed to control blue-green algal blooms in Lake Mendota. Canadian Journal of Fisheries and Aquatic Sciences, 55, 1169-1178.

Lick, W., Lick, J., \& Ziegler, C. K. (1992). Flocculation and its effect on the vertical transport of fine-grained sediments. Hydrobiologia, 235/236, 1-16.

Likens, G. E. (Ed.). (1985). An Ecosystem Approach to Aquatic Ecology: Mirror Lake and its Environment. Springer, New York, $516 \mathrm{p}$.

Lindström, M., Håkanson, L., Abrahamsson, O., \& Johansson, H. (1999). An empirical model for prediction of lake water suspended matter. Ecological Modelling, 121, 185-198.

Maki J. S., Tebo B. M., Palmer F. E., Nealson, K. H., \& Staley, J. T. (1987). The abundance and biological activity of manganese-oxidizing bacteria and Metallogenium-like morphotypes in Lake Washington, USA. FEMS Microbiology Ecology, 45, 21-29.

Malmaeus, J. M., \& Håkanson, L. (2004). Development of a lake eutrophication model. Ecological Modelling, 171, 35-63.

Malmaeus, J. M., \& Rydin, E. (2006). A time-dynamic phosphorus model for profundal sediments of Lake Erken, Sweden. Aquatic Sciences, 68, 16-27.

Molot, L. A., \& Dillon, P. J. (1993). Nitrogen mass balances and denitrification rates in central Ontario lakes. Biogeochemistry, 20, 195-212.

Molot, L. A., \& Dillon, P. J. (1997). Colour-mass balances and colour-dissolved organic carbon relationships in lakes and streams in central Ontario. Canadian Journal of Fisheries and Aquatic Sciences, 54, 2789-2795.

Monte, L., Brittain, J. E., Håkanson, L., Heling, R., Smith, J., Zheleznyak, M., et al. (2005). Review, assessment and rationale of models implemented in decision support systems for the management of fresh water bodies contaminated by radionuclides (pp. 21-202). In L. Monte, D. Hofman \& J. Brittain (Eds.), Evaluation and nertwork 
of EC-decision support systems in the field of hydrological dispersion models and of aquatic radioecological research assessment of environmental models and software (p. 328). Rome: ENEA.

Mosello R., \& Ruggiu D. (1985). Nutrient load, trophic condition and restoration prospects of Lake Maggiore. Internatimate Revue Der Gesamten Hydrobiologie, 70, $63-75$.

Nõges, T. (Ed.) (2001). Lake Peipsi: Hydrology, meteorology, hydrochemistry. Tallinn: Sulemees, Tartu, $163 \mathrm{p}$.

Nõges, P., Järvet, A., Tuvikene, L., \& Nõges, T. (1998). The budgets of nitrogen and phosphorus in shallow eutrophic Lake Võrtsjärv (Estonia). Hydrobiologia, 363, 219-227.

Nordvarg, L. (2001). Predictive models and eutrophication effects of fish farms. Dr. Thesis, Uppsala University, Sweden.

OECD (1982). Eutrophication of waters. Monitoring, assessment and control (p. 154). Paris: OECD.

Ottosson, F., \& Abrahamsson, O. (1998). Presentation and analysis of a model simulating epilimnetic and hypolimnetic temperatures in lakes. Ecological Modelling, 110, 223-253.

Persson, G., \& Jansson, M. (1988). Phosphorus in freshwater ecosystems. Hydrobiologia, 170, 340.

Quay, P. D., Emerson, S. R., Quay, B. M., \& Devol, A. H. (1986). The carbon cycle for LakeWashington - A stable isotope study. Limnology and Oceanography, 31, 596611.

Rusak, J. A., Yan, N. D., Somers, K. M., \& McQueen., D. J. (1999). The temporal coherence of zooplankton population abundance in neighboring north-temperate lakes. The American Naturalist, 153, 46-58.
Ryding, S.-O. (1983). The Lake Ringsjön area - Changing ecosystems. Uppsala: Uppsala University, Department of Limnology.

Sas, H. (Ed.) (1989). Lake restoration by reduction of nutrient loading: Expectations, experiences, extrapolations. Academia Verlag Richarz, St. Augustin, Germany, $497 \mathrm{p}$

Schindler, D. W. (1977). Evolution of phosphorus limitation in lakes. Science, 195, 260-262.

Schindler, D. W. (1978). Factors regulating phytoplankton production and standing crop in the world's freshwaters. Limnology and Oceanography, 23, 478-486.

Torrey, M. S., \& Lee, G. F. (1976). Nitrogen fixation in Lake Mendota, Madison, Wisconsin. Limnology and Oceanography, 21, 365-378.

Toyoda, K., \& Shinozuka, Y. (2004). Validation of arsenic as a proxy for lake-level change during the past 40,000 years in Lake Biwa, Japan. Quaternary International, 123-125, 51-61.

Wetzel, R. G. (1983). Limnology (p.767). Saunders College Pub.

Wetzel, R. G. (2001). Limnology (p. 1006). London: Academic.

Vollenweider, R. A. (1968). The scientific basis of lake eutrophication, with particular reference to phosphorus and nitrogen as eutrophication factors. Tech. Rep. DAS/ DSI/68.27, OECD, Paris, 159 pp.

Vollenweider, R. A. (1976). Advances in defining critical loading levels for phosphorus in lake eutrophication. Memorie Dell'Istituto Italiano Di Idrobiologia, 33, 53-83.

Zimmermann, U., \& Suter-Weider, P. (1976). Contributions to the limnology of Lakes Walensee, Zürich-Obersee and Zürichsee, Schweiz. Zeitschrift fuÉr Hydrologie, 38, 7196 (in German). 